\title{
XXIII.
}

\section{Ueber die Heilung von Wunden des Magens, Darmkanals und Uterus mit besonderer Beriicksichtigung des Verhaltens der glatten Muskeln.}

(Aus dem pathologischen Institut in Göttingen.)

Von Dr. Alexander Ritschl

in Göttingen.

Die Frage, in wie weit das glatte Muskelgewebe im Stande sei, sich zu regeneriren, hat erst in neuester Zeit vereinzelte Beantwortungen gefunden. Freilich hat man sich früher schon über die Neubildung glatten Muskelgewebes Vorstellungen zu verschaffen gesucht und zu dem $Z_{\text {weck }}$ die mit der Regeneration zweifellos nahe verwandte Hypertrophie glatter Musculatur, wie sie physiologisch besonders auffallend am schwangeren Uterus auftritt, in's Auge gefasst. Im Allgemeinen bestehen nun in der älteren Literatur zwei Ansichten. Die eine Gruppe von Forschern lässt junge glatte Muskelzellen lediglich durch Umwandlung von Bildungszellen, die aus Bindegewebszellen hervorgehen, entstehen, die anderen neigen dahin, eine isogenetische Neubildung durch Theilung der vorhandenen Muskelzellen anzunehmen.

Der Hauptvertreter der ersteren Ansicht ist Kölliker (Zeitschrift für wissenschaftl. Zoologie Bd.1, S. 72, 1849 und Handbuch der Gewebelehre, 4. Aufl., S. 568, 1863). Er fand nehmlich bei der Untersuchung des schwangeren Uterus in der ersten Hälfte der Gravidität in den äusseren und mittleren Schichten der Muskellage spindelförmige und ungemein lange, wellige Elẹmente, deren Kerne lang und schmal waren. In den innersten Schichten wurden sie kürzer und gingen in eine Zellschicht über, welche zugleich mit Bildungszellen des Bindegewebes und Spindelzellen die innersten Theile der Musculosa bildeten. Kölliker führt somit die Neubildung von glatten Muskelfasern auf die 
Umwandlung von Bildungszellen, welche wieder Abkömmlinge von Zellen des Bindegewebes sind, zu contractilen Faserelementen zurück.

Diese Beobachtung fand Förster (Handbuch der allgemeinen pathologischen Anatomie. S. 260) bei Untersuchungen des bypertrophischen Uterus und kleiner Myome bestätigt, spricht sich aber auch dahin aus, dass eine Neubildang der Zellen durch Theilung physiologischer Muskelzellen nicht ausgeschlossen sei.

Der Ansicht Kölliker's schloss sich auch Rindfleisch in seiner pathologischen Histologie an.

Während die genannten Forscher die Neubildung von glatten Muskelfasern aus Bindegewebe durch besondere Bildungszellen vermittelt sein lassen, nimmt Aeby (Reichert's Archiv. 1861. S. 643) an, dass in den Eierstöcken der Wirbelthiere eine directe Umwandlung ausgebildeter Bindegewebskörperchen zu contractilen Faserzellen in der Weise erfolge, dass die ersteren contractile Substanz in sich aufnähmen, bei deren Schwinden die Muskelfaser wieder zur Bindegewebsfaser werde.

Ehe ich derjenigen Forscher gedenke, welche dem obenerwähnten zweiten Modus der Muskelzellenvermehrung das Wort reden, möchte ich noch einer Beobachtung Arnold's Erwähnung thun, da dieselbe unter dem Kapitel der Neubildung glatter Muskeln noch in neueren Lehrbüchern mehrfach citirt wird. Arnold (dieses Archiv Bd. 39. S. 270) hatte nehmlich in einem Fall von eitriger Pleuritis innerhalb schwartiger Auflagerungen eine Gewebsschicht gefunden, die aus bündelweis gruppirten spindelförmigen Zellen bestand. Diese Zellen beschrieb er als glatte Muskelzellen, indem er annahm, dass dieselben wie im schwangeren Uterus, so auch hier aus Bindegewebe hervorgegangen seien. Diese Ansicht wurde jedoch von Neumann (Archiv für Heilkunde. X. 1869. S. 600) an der Hand von 3 Fällen von eitriger Pleuritis, die im Einzelnen denselben Befund ergaben wie der Arnold'sche, widerlegt und der Irrthum des letzteren dadurch aufgeklärt, dass er als Hauptkriterium für die Identität der fraglichen Spindelzellen mit glatten Muskelzellen die Möglichkeit ihrer Isolirung durch bestimmte Reagentien ( 1 pCt. Essigsäure, 35 pCt. Kalilauge, 20 pCt. Salpetersäure) angesehen hatte. Neumann weist nun nach, dass jene Spindelzellen nichts 
als Bindegewebszellen sind. Er stützt sich dabei auf zwei Thatsachen: einmal fand er an vielen dieser spindelförmigen Zellen eine deutliche pinselartige Zerspaltung der Enden in ein Büschel feiner, homogener, wellig geschlängelter Fibrillen, welche die grösste Aehnlichkeit mit Bindegewebsfibrillen hatten. Diese Zellen hält er für identisch mit den zuerst von Schwann, später von M. Schultze und anderen beschriebenen Bildungszellen des Bindegewebes. Zweitens aber fand er bei einem Vergleich der fraglichen Spindelzellen mit einem an Spindelzellen reichen Bindegewebe - er nahm dazu eine in Heilung begriffene, von ihm durchschnittene Achillessehne des Kaninchens - keinerlei charakteristische Unterschiede zwischen beiden. Auch sah er seine Annahmen bestätigt durch eine fernere Vergleichung jener Spindelzellen mit Spindelzellen aus sarcomatösen Geschwülsten. Bei beiden Versuchsobjecten war ein Vorhandensein glatter Muskelfasern, also auch eine Verwechselung mit solchen, absolut ausgeschlossen. Endlich war auch das Verhalten dieser zum Vergleich herangezogenen Zellen gegen Reagentien dasselbe wie der in den pleuritischen Schwarten aufgefundenen Zellen.

Die ersten genaueren Untersuchungen über Vermehrung glatter Muskelfasern durch Theilung datiren aus dem Jahre 1862, wo Moleschott und Piso-Borme (Untersuchungen zur Naturlehre des Menschen und der Thiere. IX. S. 1-6) eingehendere Studien über das Vorkommen gabelförmiger Theilungen an glatten Muskelfasern veröffentlichten, nachdem Moles chott schon im Jahre 1859 (Untersuchungen zur Naturlehre. Bd. VI. S. 388) auf das Vorkommen dichotomisch gespaltener Muskelfasern des menschlichen Darms aufmerksam gemacht hatte. Die genannten Forscher machten ihre Beobachtungen besonders am schwangeren Uterus des Menschen, aber auch an anderen, glatte Muskelfasern enthaltenden Organen des Menschen und einzelner Thiere. Sie deuteten diese Theilungsvorgänge, die einmal in einer von beiden Enden der Faser aus gegen die Mitte fortschreitenden Spaltung, andere Male in einer Ast- und Knospenbildung bestanden, als einen Modus der Vermehrung, zumal sie ihre meisten positiven Befunde dem Studium des schwangeren Uterus verdankten, der ja von vornherein in dieser Hinsicht eine reiche Ausbeute erwarten liess. Das Vorkommen zweier Kerne innerhalb einer 
Muskelzelle bezeichnen sie als ein sehr seltenes Ereigniss und wagen es deshalb nicht, einen nothwendigen Zusammenhang zwischen der Vermehrung der Fasern und der Theilung der Kerne anzunehmen.

Vor dieser genaneren Untersuchung finden wir Angaben über gabelförmige Theilungen glatter Muskelfasern schon bei Schiff (Jenaische Annalen für Physiologie. Bd. II. Falsches Citat von Moleschott und Piso-Borme, Untersuchungen zur Naturlehre des Menschen. Bd. 9. S.1), der solche im Uterus des Meerschweinchens wahrgenommen hat. Auch Aeby (Archiv für Anatomie und Physiologie von Reichert und Du Bois-Reymond. 1861. S. 637) hat solche Muskelfasern im Ovarium von Fröschen aufgefunden.

Im Jahre 1871 fand endlich noch Durante bei seinen Untersuchungen über die pathologisch-anatomischen Verhältnisse der Gefässe bei acuten Entzündungsvorgängen in der Wảnd der Vena jugularis die Muskelzellen gewuchert. Ackermann referirt über die Arbeit Durante's (Wiener medicinische Jahrbücher. 1871. Heft 3. S. 321-334), die mir leider selbst nicht zugänglich war, im Jahresbericht von Virchow and Hirsch, 1871, S. 214 folgendermaassen: „Die Kerne in den Faserzellen der Media erschienen gewuchert und die Zellen selbst durch Lymphkörperchen auseinander gedrängt, oder auch selbst gespalten und zwar durch bald quer, bald schief, bald etwas gebogen umlaufende Linien in eine Reihe kurzer Cylinderchen, deren jedes einen bis zwei Kerne enthielt."

Eine Entscheidung über den wahren Sachverhalt bei der Vermehrung glatter Muskelfasern konnten die angeführten Beọbachtungen und Untersuchungen nicht bringen, und so schloss man sich je nachdem entweder der einen oder der anderen der oben ausgeführten Ansichten an, oder hielt beide Arten der Vermehrung für möglich. Doch fehlte noch immer jegliche Auskunft über die Regenerationsfähigkeit des glatten Muskelgewebes.

Die erste Arbeit über die Regeneration glatter Maskelfasern verdanken wir einem Russen, Jakimowitsch, der im Jahre 1879 (Medicinisches Centralblatt. 1879. S. 897) eine vorläufige Mittheilung über seine im Laboratorium des Prof. Peremeschko in Kiew ausgeführten Untersuchungen über unseren Gegenstand 
machte, der er später eine ausführliche Arbeit (Dissertation. $1880 \mathrm{Kiew})$ folgen liess. Einen genauen Bericht Mayzel's über diese Arbeit findet man im Jahresbericht über die Fortschritte der Anatomie und Physiologie von Hofmann und Schwalbe, 9. Bd. S. 61-63. Es würde mich zu weit führen, hier näher auf diese Arbeit einzugehen, doch will ich erwähnen, dass Jakimowitsch an Kaltblütern (Rana esculenta, Triton criscatus, Salamandra) und Säugethieren (Hund und Ferkel) experimentirte, als Reagentien Ammonium bichromicum, Chromsäure, Alkohol und die Vergoldungsmethode verwandte und zu dem Resultat kam, dass die glatten Muskelfasern sich auf dem Wege der sogenannten directen Kerntheilung vermehren und regeneriren können. Was man gegén diese Resultate einwenden kann, haben Stilling und Pfitzner am Ende ihrer Abhandlung über die Regeneration glatter Muskeln (Archiv für mikroskopische Anatomie. Bd. XXVIII. S. 410) ausgeführt. Letztere Arbeit darf, was die Behandlung dieses Themas beim Kaltblüter anbelangt, als mustergültig angesehen werden. Freilich hatten die letztgenannten Forscher vor Jakimowitsch den Vortheil, dass inzwischen Flemming mit seinen epochemachenden Untersuchungen über Zellenneubildung hervorgetreten war und gelehrt hatte, den Kern im Zustand der Kinese durch bestimmte Reagentien zu fixiren und durch gewisse Färbungsmethoden im mikroskopischen Bilde deutlich bervortreten zu lassen. Stilling und Pfitzuer, welche am Magen des durch seine Fähigkeit, verloren gegangenes $\mathrm{Ge}$ webe zu regeneriren, besonders ausgezeichneten Triton taeniatus experimentirten, kamen zu dem Resultat, dass dieser Defecte der Muscularis volkommen zu regeneriren im Stande sei, und zwar nicht, wie Jakimowitsch meint, auf dem Wege der directen, sondern der indirecten Kerntheilung.

Kurze Zeit vor Veroffentlichung der letzteren Arbeit hat auch Busachi, ein Schüler Bizzozero's (vorläufige Mittheilung im Centralblatt für medicinische Wissenschaften 1887, S. 113. Giornale della R. Academia di Med. di Torino, Anno 49, No. 3-4, p. 55) nach Verletzung des Dünndarms am Hunde während der Narbenbildung in den glatten Muskelfasern eine deutliche Vermehrung durch Karyokinese sowohl in der Tunica muscularis propria, als auch in der Tunica muscularis mucosae gefunden 
und bei weiteren Untersuchungen der Maskelzellen der Prostata und Harnblase des Hundes, des Dünndarm und der Gebärmutter des Kaninchens und Meerschweinchens dieselben Resultate erlalten, endlich auch in einem Fall von Krebs der Vorhaut um die Krebszapfen Vermehrung der glatten Muskelzellen durch Karyokinese beim Menschen beobachtet.

Noch ehe die Arbeit Stilling's und Pfitzner's erschienen war und Busachi über die Resultate seiner Untersuchungen Mittheilung machte, schlug mir mein hochverehrter Lehrer, Herr Professor Orth, veranlasst durch den Befund von Karyomitosen an den Muskelzellen mehrerer einige Tage vorher mit einem Sondenknopf leicht mechanisch insultirter Kaninchenaorten, vor, das Verhalten der glatten Muskeln des Magendarmkanals und des Uterus nach Verletzungen zu untersuchen. Leider musste ich meine Arbeit wegen anderer an mich gestellter Aufgaben im Winter unterbrechen und bin deshalb erst jetzt im Stande, meine Beobachtungen vorzulegen, welche indessen auch nach den erwähnten Publicationen zur völligen Klärung der Frage nicht ohne Interesse sein dürften.

Bei meinen Untersuchungen beschränkte ich mich darauf, das Verhalten der glatten Muskelfasern während der Verheilung eines Defectes beim Warmblüter festzustellen. Das dazu erforderliche Material wurde experimentell gewonnen, und zwar dienten mir als Versuchsthiere lediglich Kaninchen, bei denen ich mich wieder an die am leichtesten zugänglichen und an glatten Muskeln reichsten Organe: Magen, Darm und Uterus hielt.

Zum Zweck der Operation wurde das narkotisirte Thier in Rückenlage auf einem geeigneten Brett mit Kopfhalter befestigt und die Narkose während der Operation unterhalten. Bei der Operation wurde der Antisepsis möglichst Rechnung getragen, also zunächst von der Bauchhaut an der Einschnittsstelle mit Scheere und Rasirmesser die Haare entfernt und das Operationsfeld mit Sublimat- oder Carbollösung gründlich desinficirt. Je nach dem Organ, an welchem später eine Wunde etablirt werden sollte, wurde zur Eröffnung der Bauchhöhle eine höhere oder tiefer gelegene Stelle gewählt. Der Schnitt verlief stets genau im Verlauf der Linea alba und wurde etwa so lang gemacht, dass man nachher eben zwei Fingerspitzen in die Bauch- 
höhle einführen konnte. Das Peritonäum wurde stets vorsichtig über der Hohlsonde geöffnet, nachdem in eine mit der Pincette emporgehobene Falte ein kleiner Einschnitt gemacht war. Lagen somit die Eingeweide vor, so wurde das betreffende Organ mit den Fingern hervorgezogen. Bisweilen kostete es Schwierigkeiten, den stets mit Nahrung mehr oder weniger prall gefüllten Magen zu fixiren, indessen wurden diese Schwierigkeiten deshalb in Kauf genommen, weil nach unsern Erfahrungen die Thiere nach einer mehrștündigen Nahrungsentziehung den Eingriff lange nicht so gut überstanden. Aus der Wand des von einem Assistenten fixirten Organs wurde nun an einer von Blutgefässen möglichst freien Stelle ein Stückchen mit der Scheere herausgeschnitten. Am Magen gelang es fast immer, weniger gut an dem mit einer sehr schmalen Muscularis versehenen Dünndarm die Mucosa unverletzt zu lassen. Am Uterus, wo eine Infection von Seiten des Inhalts weniger $z$ u befürchten war als an den Organen des Verdauungskanales, wurde jedesmal bis in's Lumen eingeschnitten. Im Allgemeinen vermieden wir durch die genannten Cautelen den Eintritt stärkerer Blutungen, kamen jedoch solche vor, so liessen sie sich meist durch die Naht leicht stillen. Bei dem mit einer sehr kräftigen Muscularis versehenen Magen vermieden wir es möglichst, noch beim Nähen mit der Nadel die Mucosa zu verletzen und führten deshạlb die Fäden nur durch die Ränder der klaffenden Muskelwunde. Beim Darm und Uterus musste schon blos des, nöthigen Haltes wegen die Naht auch durch die Mucosa mitgelegt werden. Schliesslich wurde die Wunde und ihre Umgebung noch einmal mit antiseptischen Flüssigkeiten gereinigt und mit etwas Jodoform bestreut in den Bauchraum versenkt. Die Bauchwunde wurde mit tiefen, das Peritonäum noch mitfassenden Nähten geschlossen und durch oberflächliche Nähte noch klaffende Hautstellen vereinigt. Zum Schluss wurde die Bauchwunde noch einmal mit Sublimatlösung desinficirt and reichlich mit Jodoform bestreut und eingerieben. Ein Verband liess sich in Folge letzterer Methode ohne jeden Nachtheil entbehren. Die Thiere überstanden die Operation in der Regel sehr gut und waren, nachdem sie die Nachwirkungen der Narkose überwunden hatten, von nicht operirten kaum zu unterscheiden. Jedes Thier. wurde in der Regel zu zwei an getrennten 
Organen und zu verschiedenen Zeiten ausgeführten Operationen benutzt, so dass immer zwei Präparate gewonnen wurden, welche verschiedene Stadien der in Heilung begriffenen Wunde repräsentirten. In einer Sitzung an mehreren Stellen zu operiren, erwies sich als misslich, so dass wir uns bald darauf beschränkten, zur Zeit nur an einer Stelle eine Wunde anzulegen, nachdem zu Anfang mehrere Thiere in Folge mehrerer gleichzeitig ausgeführter Operationen noch im Verlauf desselben Tages gestorben waren.

Zur Gewinnung beweiskräftiger Präparate lag es in unserm Interesse, dieselben vom eben vorher getödteten Thier zu erhalten. Allerdings war es nicht immer der Fall, dass die Kaninchen eine oder gar zwei Operationen so gut überstanden, dass sie noch unbestimmte Zeit gelebt hätten. War ein Thier deshalb dem Ende nahe, so wurde es noch möglichst vor dem Ableben getödtet, dagegen von bereits verstorbenen Thieren nur ausnahmsweise Präparate zubereitet. Ich bemerke, dass alle meine Präparate, wo ein darauf bezüglicher Vermerk fehlt, von Thieren stammen, die unmittelbar vor Entnahme der Präparate getödtet waren.

Dem Leben der Versuchsthiere wurde durch den Genickschlag und die darauf folgende Durchschneidung der grossen Halsgefässe ein Ende gemacht. Sodann ward die Bauchhöhle schnell eröffnet und die Operationsstelle, die in der Regel leicht zu finden war, mit ihrer Umgebung herausgeschnitten. Auffallende Veränderungen wurden nachher notirt. Die gewonnenen Präparate kamen dann so schnell als möglich in Flemming'sche Chrom-Osmium-Essigsäure-Lösung. Um eine schnelle Einwirkung der Fixationsflüssigkeit auf die Gewebe zu erzielen, wurden dieselben im gegebenen Fall in der nöthigen Weise verkleinert. In der Lösung blieben die Stückchen 1-2 Tage lang liegen, wurden dann in fliessendem Wasser 1 Tag ausgewaschen und einen Tag lang in absolutem Alkohol nachgehärtet. Danach wurden sie entweder sofort zur Einbettung vorbereitet, oder in 70 procentigem Alkohol conservirt.

Zur Anfertigung der zur mikroskopischen Untersuchung nothwendigen Schnitte wurde entweder die Einbettung in Paraffin oder in Celloidin gewählt, letztere vorzugsweise dann, wenn die Heilung noch nicht soweit vorgeschritten war, dass man bei 
den späteren Manipulationen ein Auseinanderfallen der durch die Operation getrennten Gewebe befïrchten musste.

Die Schnitte wurden mit Hälfe des Mikrotoms in einer Dicke von $0,01-0,03 \mathrm{~mm}$ angefertigt.

Zur Färbung meiner Präparate bediente ich mich ausschliesslich des Saffranins und zwar anfangs in einer alkoholisch wässrigen Jösung. Ich liess die Schnitte darin 12-24 Stunden liegen, spülte sie dann in salzsaurem Alkohol (Alcohol absolut. 100, Acid. hydrochloric. 0,5) ab, brachte sie dann kurze Zeit in absoluten Alkohol und conservirte sie nach Aufhellung in Xylol in Canadabalsam.

Später benutzte ich ausschliesslich eine wässrige Lösung von Saffranin 1:2000 Aq., die schon nach kurzer Zeit, $\frac{1}{2}$ bis 1 Stunde eine treffliche Kernfärbung, speciell der in Mitose begriffenen Kerne bewirkt. Es genügte hier auch meist ein ganz kurzes Eintauchen der Schnitte in salzsauren Alkohol, um die Kernfärbung gehörig hervortreten zu lassen.

Ich lasse nun die Beschreibúng meiner Präparate folgen, die ich nach der Zeit, welche zwischen der Operation und der Section liegt, geordnet habe.

1.

20 Stunden. Dickdarm. Operation am 8. März 1886, Section am 9. März.

Die beiden Schnittfläcben sind sehr gut adaptirt und durch ein frisches Fibringerinnsel verklebt. Es feblen noch jegliche Anzeigen einer Gewebswucherung, sowohl im Binde- wie im Muskelgewebe.

2.

2 Tage. Uterus. Operation am 13. April rs86. Aus dem Theil des Uterns, wo beide Hörner bereits vereinigt sind, wurde auf der vorderen Seite, der Längsaxe parallel, ein Stückehen Gewebe herausgeschnitten. Die ziemlich heftige Blutung stand nach der Naht gut.

Section am 15. April 1886. Wunde mit einen Blutcoagulum bedeckt, nicht adhärent.

Mikroskopischer Befund. Die zur Längsaxe im rechten Winkel angeferiigten Schnitte zeigen die beiden durch Gewebe vereinigten Uterus hörner quer durchschnitten und demgemäss zwei wit drüsigen Ausbuchtungen versehene Lumina, die mit Cylinderepithel bekleidet sind. Die MIuscularis ist in beiden Hörnern derartig getroffen, dass die äussere Lage quer, die innere längs durchschnitten ist. In letzterer erscheinen die Muskelbündel in ihrem Verlauf vielfach durcheinander verworren und durch Bindegewebe mehr oder weniger aus einander gedrängt und isolirt. 
Der Defect ist durch ein sich $z$ wischen die Wundränder einschiebendes und diese auf der Oberfläche noch eine Strecke weit überragendes Blutgerinnsel ausgefülit. In der Gegend um die Wunde zeigt die zumeist der äusseren, quer getroffenen Schicht angehörige Musculatur ein eigenthümliches Verbalten: Die Kerne der Muskelfasern sind nehmlich auffallend stark gefärbt und zum Unterschied von normalen Huskelkernen vollkommen homogen. Ausserdem erscheinen die einzelnen Muskelzellen auffallend verschmälert und daber dicbt an einander gedrängt, wie zusammengepresst. Ich bin der Meinung, dass es sich bier um eine Verklumpung des Chromatingerüstes jm Kern handelt und eine beginnende Nekrose, wie auch Stilling und Pfitzner (Archiy für mikrosk. Anatom. Bd. XXVIII. S. 407 u. 408 und Abhandlung „zur pathol. Anatomie des Zellkerns", dies. Arch. Bd. 103. S. 287) annehmen. An anderen Stellen fehlt jedoch jede Kernfärbung und auch das Protoplasma der Muskelfasern erscheint im Vergleich zu dem normaler Muskelzellen desselben Präparates durchscheinender, ein Zeichen, dass hier bereits vollkommene Nekrose eingetreten ist. Ferner findet man an einzelnen Stellen deutlicher als an anderen innerhalb dieser veränderten Gegend Mengen chromatophiler Körnchen, die sich $z$ wischen und innerbalb absterbender und abgestorbener Muskelfasern befinden und auch im Bindegewebe der Umgebung nicht fehlen. Man darf diese Gebilde wohl als zerfallene Leukocyten betrachten, da sie sich auch in grössèrer Menge innerbalb geronnener Blutmassen vorfanden. Auch in der weiteren Umgebung des Defectes erscheinen die der Oberfläche nahe gelegenen Muskeln nekrotisch, was vielleicht auf eine Oberflächenwirkung des angewandten Desinficienz zuräckgeführt werden muss. Ausserdem trifft man hier gerade zerstreut liegende Leukocyton mit charakteristischer Kernfärbung.

In den tieferen Schichten der Uteruswand befinden sich zum Theil recht umfangreiche Hämorrhagien $\overrightarrow{1} \boldsymbol{m}$ Gewebe, vermutblich in Folge von Quetschung bei der Operation entstanden, in deren Bereich und Umgebung sowohl Bindegewebs- wie glatte Muskelzellen oft in erheblicher Zahl mit karyomitotischen Figuren verseben sind. Auch fanden sich daselbst vereinzelte Mitosen in Capillarendothelien.

Was die Regeneration an Stelle des Defectes betrifft, so ist dieselbe noch wenig energisen im Gange. Die bezeichneten abnormen Regionen in der Umgebung des Defectes sind in grossen Ganzen frei von Mitosen, dagegen findet man in dem jenseits derselben gelegenen Binde- und Nuskelgewebe bereits Mitosen, wenn auch in geringer Anzahl. An Capillaren waren Anzeigen ron Wucherung noch nicht zu bemerken. In den Epithelien der Mucosa waren Mitosen nicht vorhanden.

3.

4 Tage. Uterus. Operation am 12. Mai 1886, Section am 16. Mai. Das Thier wurde 4 Stunden nach dem spontan erfolgten Tode secirt; Todesursache nicht aufzufinden.

Wegen der erst noch 4 Stunden post mortem erfolgten Einlegung des 
Präparates in Flemming'sche Lösung durfte man erwarten, dass die Mitosen sich während des Absterbens der Zellen vollendet hätten und in den Zustand rubender Kerne übergegangen seien. $\mathrm{Da}$ das Präparat sonst nichts Bemerkenswerthes enthält, so will ich nur erwähnen, dass trotz der Zeit, die nach dem 'Tode verflossen war, vereinzelte Mitosen an Stellen um die Verwundung sowohl in Bindegewebs- wie Iuskelzellen enthalten waren und auch im Epithel der Schleimhant Kerntheilungsfiguren aufgefunden wurden.

4.

5 Tage. Magen. Operation am 29. April 1886, Section am 3. Mai. Wunde mit einem Blutcoagulum bedeckt.

Bei der Operation ist die Tunica muscularis propria total durchtrennt und auch in der Submucosa ein Defect entstanden. In der Umgebung des Defectes sind die Muskeln in ziemlich erheblichen Umfang nekrotisirt, erscheinen bell, hyalin und ihre Kerne sind nicht gefärbt. In der anmittelbaren Umgebung des Defectes sind sie noch von chromatophilen Körnehen reichlich durchsetzt. Nach der Peritonäalhöhle zu bedeckt die Wunde ein Fibringerinnsel, welches in Zerfall begriffene rothe und farblose Bluthörperchen enthält. Ebenso findet man Fibringerinnsel in der Submucosa neben Blutkörperchen nicht nur dicht am Defect, sondern auch noch eine Strecke. weit seitlich von diesem.

Die Regeneration ist, nach der Zabl der Mitosen zu sebliessen, recht energisch im Gange. In der Umgebung der Wunde, wo allgemeine Nekrose ohne Entzündung herrscht, - vielleicht sind anch hier die Antiseptica schuld - ist natürlich keine Zellwucherung möglich. Erst wo normales Gewebe an nekrotisches stösst, beginnt die Region für die Zellvermehrung. Hier findet man demgemäss auch grosse Mengen von Mitosen sowohl in Bindegewebs-, wie Mnskelzellen und Endothelzellen von Capillaren. Auch hier beschränkt sich die Zone der Wucherungszustände nicht nur auf die nächste Ungebung der Trennungslinie des normalen und nekrotischen Gewebes, sondern dehnt sich noch eine erbebliche Strecke weit in das normale Gewebe bin aus. Gegen den Wundwinkel zu wird der nekrotische Theil der Muscularis immer schmaler, so dass man schliesslich an Stellen kommt, wo die Wundränder von lebendem MIuskelgewebe gebildet, durch ein schmales Fibringerinnsel verklebt, dicht an einander liegen. Gerade bier findet man häufig in Theilung begriffene Nuskelzellen dicht an den schmalen Defect heranreichen. Gleichzeitig finden sich in den Maschen des Fibrins junge Bindegewebszellen (Fibroblasten), zum Theil in Karyokinese begriffen. Wie an den anderen Präparaten findet man auch hier Karyomitosen in der Muscularis und dem dazugebörigen Bindegewebe noch eine erbebliche Strecke weit vom Defect entfernt. Danach ist's auch natürlich, dass man in Sehnitten, die dem ausserbalb des Wundwinkels gelegenen Gewebe entnommen sind, noch eine Strecke weit Mitosen in der Magenwand findet.

In der Submucosa trifft man Mitosen ziemlich reichlich in der Ungebung und in den Maschen der oben beschriebenen Fibrinmassen. 
Auffallend viel Mitosen glatter Muskeln sind in der Muscularis mucosae entbalten, zumal an solchen Stellen, welche dem Defect gegenuber liegen und besonders in solchen Präparaten, wo in der Umgebung des Defectes die Muscularis in grösserer Ausdehinung nekrotisch ist. Es scheint danach, als wenn hier die Mnscularis mucosae eine Hyperplasie erlitte, um vicariirend für die Tunica muscularis propria im weiteren Verlauf der Heilung einzutreten, wo noch ein grösserer Substanzverlust in der Magenwand durch Abstossung der nekrotischen Massen zu erwarten sein dürfte.

In der Mucosa sind Drüsenepithelien in mässiger Menge in Karyokinese begriffen. Dieselben feblen ganz und gar dem Oberfiächenepithel, die oberen Theile der Drüsen enthalten die Mitosen am reichlichsten, während jhre Zahl gegen den Fundus zu mehr und mehr abnimmt, und die der Muscularis mucosae zu gelegenen Partien ihrer fast ganz entbehren.

5.

5 Tage. Uterus. Operation am 5. April 1886. Es wurde ein Stäck aus einem Uterushorn mit vollkommener Perforation der Wand durch einen parallel zur Längsaxe verlaufenden Scheerenschnitt exstirpirt. Ziemlich beftige Blutung, die nach der Naht stand.

Section am 10. April. Auf der verwundeten Stelle befand sich ein Blutgerinnsel, keine entzündlichen Erscheinungen.

Mikroskopischer Befund. Der Defect reicht in vielen Präparaten bis in's Lumen des Uterusschlauches, in anderen nahe dem Wundwinkel mehr oder weniger weit in die Muscularis. Letztere besteht aus einer inneren circulären und äusseren longitudinalen Lage. Durch den Schnitt ist die erstere längs, die letztere quer getroffen. Zwischen den Wundrändern befindet sich ein Blutcoagulum, welches noch eine ziemlich erhebliche Strecke sich auf der Oberfläche des Uterus hin erstreckt. Die gesammte Umgebung des Defectes ist in lebhafter Wucherung begriffen, was aus der grossen Zah! von Karyomitosen zu schliessen ist, welche in Bindegewebs- und Muskelzellen nicht nur in der unmittelbaren Umgebung des Defectes, sondern noch eine erhebliche Strecke von diesem entfernt zu finden sind. Diese Beobachtung trifft auch für jene, der Nähe des Wundwinkels entrommenen Präparate zu, nnd zwar in der Weise, dass auch die hier nicht, defecte innere Muskellage zablreiche in Kerntheilung begriffene Zeilen enthüt.

In Capillarendothelien fanden sich innerbalb der Regenerationszone ebenfalls vereinzelte Mitosen.

Die Mucosa enthält in sämmtlichen Präparaten in Kerntheilung begriffene Epithelzellen. Dass eine grössere Anzah! derselben an Stellen liegen, die der Wunde näher oder benachbart sind, war bei dem überbaupt nur vereinzelten Vorkommen derselben kaum zu constatiren.

6.

6 Thage. Magen. Operation am 31. März, Section am 6. April 1886. Netz mit der Magenwunde verwachsen. 
Mikroskopischer Befund. Der Defect trennt in den meisten Schritten die Muscularis vollständig. Nach den Wundwinkeln zu erhält man auch Präparate, wo nach der Nucosa zu die Muscularis noch zum Theil zusaımenhängt. Zwischen den klaffenden Wundrändern befindet sich ein stark fibrinhaltiges Blutcoagulum, welebes sich auch in die Submucosa hinein erstreckt und auf der der Bauchböhle zugewandten Seite das Netz an den Magen heftet. Innerhalb dieser Ausfüllungsmasse des Defectes findet man reichlich junge Bindegewebszellen (Fibroblasten), welche zum Theil in Karyomitose begriffen sind, ebenso in der Umgebung des Defectes in Kerntheilung begriffene Bindegewebszellen. Anch die Zellen der Submucosa zeigen Karyomitosen, besonders in Schnitten, wo dieselbe selbst defect erscheint.

Die Muskelfasern der Tunica muscularis propria enthalten Mitosen in ziemlich reichlicher Menge, sowohI in der directen Umgebung des Defectes, als auch noch eine Strecke weit von dieser entfernt, bis sie schliesslich nur noch ganz vereinzelt $z u$ finden sind und sich dann ganz verlieren. In der von der Verwundung nicht mitbetroffenen Muscularis mucosae kommen in der Defectstelle nahe gelegener Partien Mitosen in Muskelzellen, wenn auch nicht so reichlich wie in der Tunica muscularis propria vor, besonders zahlreich in solchen Präparaten, wo die letztere vollkommen und noch ein Theil der Submucosa mit durchtrennt ist.

Auch in den Endothelien der in der Umgebung des Defectes gelegenen Capillaren waren hin und wieder Mitosen zu finden.

Innerhalb der Mucosa zeigten die Epithelzellen der Drüsenschläuche reichliche Mitosen; an verschiedenen Stellen verschieden häufig; es war aber nicht zu verkennen, dass die Zahl derselben, je weiter man sich vom Defect der Muskelwand entfernte, allmählich abnahm.

Das Netz haftet, wie gesagt, an einer Stelle durch Vermittlung des den Defect ausfüllenden Blutcoagulums an der Magenwand. An einer anderen Stelle ist die Verbindungsmasse zwischen Netz und Serosa des Magens schon rein zellig. Hier wie dort enthalten die Zellen häufig Mitosen. Auch im Netz selbst fallen an Stellen, die.in keinerlei directer Beziebung zu den VerJöthungsstellen zu stehen scheinen, nicht unerhebliche Mengen von in Kerntheilung begriffenen Bindegewebszellen auf. Auch fand ich bier in der Wandung grösserer Gefässe Mitosen, von denen eine deutlich in einer Muskelfaser der Tunica media gelegen war.

\section{7.}

7 Tage. Magen. Operation am 3. August 1886. Exstirpation eines Stückchens aus der Magenwand in der gewohnten Weise. Darauf wurden einige Tropfen verdünnten Crotonöls (Ol. croton. 1, Ol. oliv. 50), um eine Entzündung zu erregen, auf die Wunde applicirt, einige Zeit einwirken geIassen und dann mit einem Schwamm abgetupft.

Section am 10. August. Die Wunde war mit dem darüber liegenden linken Leberlappen verwachsen. Auf einem Durchschnitt senkrecht auf den 
Verlauf der Wunde fand sich zwischen Magen und Leber ein erbsengrosser Heerd, der mit gelblichem Eiter erfüllt war.

Mikroskopischer Befund. Die unregelmässig gestalteten Wundränder klaffen und reichen bis in die Submucosa hinein. Seitlich von dem Defect ist die Muscularis propria eine Strecke weit nekrotisch und besonders in der directen Umgebung des Defectes mit stark gefärbten Körnchen durchsetzt; daneben finden sich auch Eiterkörperchen in mässiger Menge. An die nekrotischen Theile der Muscularis schliesst sich dann mehr oder weniger normales Muskelgewebe an, welches ziemlich grosse Mengen von kleinen polynucleären Rundzellen enthält, die darauf hindeuten, dass auch hier eine entzündliche Affection Platz gegriffen hat. Die Leber. haftet auf der einen Seite des Defectes in erheblicher Ausdehnung an der Serosa des Magens und wird hier durch hin und wieder noeh mit Fibrinfäden durchsetztes Bindegewebe festgehalten. Auf der anderen Seite dagegen deutet ein nur schmales Fibringerinnsel, welches bei der Behandlung der Schnitte meist zerriss, auf einen Zusammenhang zwischen Magen und Leber hin.

Die Submucosa enthält in der Umgebung des Defects ein von der Ausfüllungsmasse desselben ausgehendes Fibringerinnsel, welches sich noch eine ziemlich weite Strecke zwischen die Bindegewebsbälkchen derselben in feinen Netzen einschiebt und in der Nähe der Wunde ebenfalls mit Eiterkörperchen infiltrirt ist.

Trotz der augenscheinlich ziemlich beftigen Entzündung ist doch das normale Gewebe im Umkreis des nekrotischen in lebhafter Wucherung begriffen. Besonders lebbaft findet eine Vermehrung des Bindegewebes statt, vorzüglich in jener Schicht, welche den Magen mit der Leber verbindet, ferner aber in der vom Fibrin erfüllten Partie der Submucosa und im Gebiet der Muscularis im intermusculären Bindegewebe. Die Musculatur selbst enthält in Ganzen nur mässige Nengen von Kerntheilungsfiguren und zwar in einer breiten Zone, die sich an die nekrotischen, in der directen Umgebung des Defectes gelegenen Muskelfasern anschliesst. Verfolgt man die Muskeln noch weiter, so findet man schliesslich ganz normale Zellen, ohne zellige Infiltration, in denen auch keine Mitosen mebr vorhanden sind. An einzelnen Stellen sieht man sehr schön, wie auf der Grenze zwischen den nokrotischen und in Wucherung begriffenen Muskeln karyomitotische Figuren in Muskelfasern vorhanden sind, welche darauf hindeuten, dass nicht nur dem Absterben von Muskelfasern hier ein Ziel gesetzt ist, sondern dass hier noch eine Vermebrung der Muskelelemente stattindet.

Die Muscularis mucosae enthält durchweg Mitosen in ziemlicher Anzahl, die wenig geregelt, bald in der Nähe der Verletzung, bald mehr oder weniger weit von ihr entfernt liegen.

Die Drüsenepithelien der Mucosa enthalten karyomitotische Figuren in verschiedener Menge und in bestimmten Regionen reichlicher, in anderen seltener. Sie sind überall in den inneren Schichten reichlicher und feblen fast ganz den der Muscularis mucosae benachbarten. Mitunter findet man auch Mitosen in dem bindegewebigen Stützgewebe. Vergleicht man die Menge der 
Mitosen innerhalb der Drüsenepithelien, so fällt auf, dass sie um so reichlicher vorhanden sind, je grösser der Defect und die ihn umgebende Nekrose im Präparat ist, um so geringer, je weniger die Darmwand gelitten hat.

In der Regenerationszone der Muscularis findet man, wenn anch nicht sehr häufig, Mitosen in Capillarendothelien.

Die Leber bietet an der Stelle ihrer Verbindung mit dem sie an den Magen heftenden Bindegewebe ein eigenthümliches Bild. An dieser Stelle findet man nehmlich eigenthümlich stark gekörnte Leberzellen, die sowohl innerhalb unveränderten Lebergewebes, als auch zwischen gesunden Leberzellen und dem Bindegewebe und endlich durch Bindegewebe ganz von dem Lebergewebe getrennt und öfter ansehnlich entfernt sind. Die Körnung dieser Zellen rührt her von kleinsten, dunklen Pünktchen, welche möglicher Weise Fettkörnchen darstellen, welche durch die Osmiumsäure der Flemming'schen Lösung ihre dunkle Farbe erhalten haben. Ein typischer Leberzellenkern ist an diesen Gebilden wegen der starken Körnung nicht mehr zu unterscheiden. Neben den letzteren finden sich, vielleicht mit ihnen in genetischem Zusammenhang stehend, Riesenzellen, welche mit den beschriebenen Gebilden die starke Körnung gemeinsam haben. Als Uebergangsstadium bin ich geneigt solche Zellen anzusehen, bei denen bereits einzelne Kerne undeutlich durch die Körnchen durchschimmern. Die Riesenzellen liegen sowobl innerhalb des Lebergewebes, als auch ganz von Bindegewebe eingeschlossen in einiger Entfernung von der Leber, am zablreichsten jedoch auf der Grenze zwischen beiden. In der Nähe dieser veränderten Partie fanden sich, wenn auch nicht häufig, in Kerntheilung begriffene Leberzellen. Doch. fand ich nie eine solche Leberzelle mit Kerntheilungsfigur, die durch Bindegewebe von dem zusammenhängenden Lebergewebe getrennt war.

8.

10 Tage. Dünndarm. Operation am 10. April 1886. Exstirpation eines Stückchens der Darmwand dem Ansatz des Mesenteriums gegenüber inclusive Mucosa. Bei der Operation drang etwas Darminhalt aus der Wunde hervor, kam aber nicht in die Bauchhöhle. Sorgfältige Vereinigung der Wundränder durch 7 Nähte.

Section an 20. April. Die Operationsstelle ist mit der Bauchwand verwachsen.

Mikroskopischer Befund: Der Defect dringt bis in's Lumen des Darms, welcher quer durchsehnitten zur mikroskopisehen Untersuchung kommt. Die Wundränder der Muscularis klaffen ziemlich weit auseinander und zwischen ihnen liegen die Schlingen der Vereinigungsfäden. Auf einer Seite liegt ferner innerhalb des Defectes ein Stäckchen der Schleimhaut, welches aus der Oeffnung prolabirt war. Den Defect füllt ein ziemlich voluminöses Blutgerinnsel aus, welches eine grosse Menge Eiterkörperchen enthält. Mit letzterem hängt an einer Stelle durch Vermittlung eines derben Fibringerinnsels die Bauchwand zusammen, von der ein Theil mit in das mikroskopische Präparat einbezogen ist. 
Zwischen den Fadenschlingen, welche in manchen Präparaten kranzförmig an der Defectstelle liegen, ist das Gewebe, welches eigentlich hätte vereinigt werden sollen, nekrotisch geworden und bei der Zubereitung der mikroskopischen Präparate zum Theil herausgefallen. Somit ist der eigentliche, durch die Operation verursachte Defect jetzt nicht mehr vorhanden, sondern als Wundränder sind jetzt die ausserbalb der Fadenschlinge gelegenen Gewebsränder anzusehen. Die Ungebung dieses nun vergrösserten Defectes sind bald mebr, bald weniger von Eiterkörperchen infiltrirt. Wohl in Folge der eitrigen Entzündung, die hier zweifellos obwaltet, sind die Erscheinungen der Regeneration des verloren gegangenen Gewebes merkwürdig spärlich für den 10. Tag der Verheilung. Am reichlichsten sind noch Kerntheilungen im Bindegewebe, besonders in einer Bindegewebsschicht, welche sich zwischen jenes oben beschriebene derbe Fibringerinnsel und die Bauchwand einschiebt. Auch findet man an dieser Stelle öfter Mitosen in Capillarendotbelien. Dagegen sind in der Muscularis Mitosen auffallend spärlich, kommen aber sowohl in der Tunica muscularis propria, wie in der Muscularis mucosae vor. Auffallend ist, dass an weit vom Defect entfernten Stellen, ja an solchen, welche in der Nähe der Mesenterialinsertion, also dem Defect im Querschnitt des Darms gerade gegenüber liegen, in Muskelfasern, wie im intermusculären Bindegewebe Mitosen auftreten. Es wird schwer sein zu entscheiden, ob die Verstärkung der Muscularis an dieser Stelle etwa als vicariirende Hypertrophie für die Schwächung, die die Darmwand an der gegenüberliegenden Seite erfahren hat, aufzufassen ist. In einzelnen Fällen könnte man daran denken, dass eine bei der Operation unxillkürlich durch die Fixation érfolgte Quetschung des Gewebes den Anlass zu diesen Wucherungszuständen gegeben bätte, denn man findet in der Darmwand sehr häufig Residuen kleiner Hämorrhagien in Gestalt amorphen Blutfarbstof's und hin und wieder einmal eine oder mebrere Mitosen in deren Umgebung, sowoht in Muskel- wie Bindegewebszellen, bisweilen auch gerade in der Nähe der Mesenterialinsertion.

In der Mucosa finden sich innerbalb der Epithelzellen der Drüsen karyomitotische Figuren in reichlicher Menge und zwar in allen Theilen des Querschnitts im Allgemeinen gleichmässig vertheilt. Es fällt allerdings auf, dass die grössere Zahl von Mitosen, auf den Längsdurchmesser einer Drüse bezogen, in den tieferen der Muscularis mucosae zu gelegenen Theilen sich befinden, während sie gegen das Lumen zu seltener werden und auf der Oberfläche der Zotten ganz fehlen.

Es bleibt nun noch übrig, eine Beobachtung zu erwähnen, die an der Verwachsungsstelle des Darms mit der Bauchwand gemacht wurde. Die Bauchwand ist so getroffen, dass ihre quergestreiften Muskeln querdurchschnitten sind. Letztere erscheinen als vieleckige, abgerundete Bündel mit der charakteristischen Zeichnung, welche durch die verschiedene Brechkraft der isotropen und anisotropen Substanz bewirkt wird, umgeben vom Sarcolemmschlanch mit seinen Kernen, die sich mit Saffranin intensiv gefärbt haben. Die eimzelnen Bündel sind durch lockeres Bindegewebe dicht mit 
einander verbunden. So die normalen Partien. Nach der Verwachsungsstelle hin findet man einen Theil der Sarcolemmschläuche mit ibrem Inbalt durch junges Bindegewebe, welches noch hin und wieder Karyomitosen enthält, auseinandergedrängt und in eigenthümlicher Weise verändert. Die Muskelsubstanz sieht byalin, bröckelig aus, äbnlich dem Bild der wachsartigen Degeneration, so dass man wohl annebinen darf, dass es sich hier 1 m Nekrose handelt. In der directen Ungebung dieses degenerirten Muskelgewebes finden sich nun oft mehrere halbmondförmige oder kranzförmige Riesenzellen, zum Theil innerhalb, zum Theil ausserbalb des Sarcolemmschlauches, die um so grösser sind, je weniger noch von den nekrotischen Massen, die sie umschliessen, vorhanden sind. So trifft man wohl als Endstadium des Prozesses bisweilen Riesenzellen, welche gar keinen oder nur einen ganz minimalen Rest jener bier an sich nicht mehr als degenerirten Muskel erkennbare Massen umschliessen. In einzelnen Präparaten fanden wir anch Karyomitosen in Bindegewebszellen, welche zwischen den Riesenzellen lagen. Bisweilen kamen auch solche veränderte Muskelschläuche noch von ganz normalen umgeben und von jenen der Verwachsungsstelle des Darms und der Bauchwand benacbbarten getrennt vor.

Auf den ersten Blick macht es den Eindruck, als ob die Riesenzellen an der Verwachsungsstelle des Darms mit der Bauchwand von ersterem aus gegen die Muskeln des letzteren zu Felde zögen, um diese zu Grunde zu richten. Man könnte hierbei an eine Analogie dieser Riesenzellen mit den Osteoklasten beim Knochengewebe denken. Wie diese dem Knochen Substanz entziehen und in sich aufnebmen, so könnten ja auch hier die Riesenzellen dem Muskelgewebe Abbruch thun. Indessen scheint mir, und darauf komme ich später noch einmal zurück, hier den Riesenzellen die Resorption vielleicht durcb die Entzündung zu Grunde gerichteter Muskelschlänche obzuliegen. Ich möchte wegen dieses Punktes noch einmal auf Präparat 7 verweisen, da es mir vorkommt, als wenn dort ein analoger Vorgang berrseht bei der Verwachsung des Magens mit der Leber. Hier wie dort herrscht eitrige Entzündung, hier Degeneration und Nekrose von quergestreiften Muskeln, dort fettige Degeneration von Leberzellen, hier und dort Riesenzellen die $z u$ den degenerirten Geweben zweifellos in Beziehung stehen.

In dem Gewebe um die so veränderten Muskelbündel fanden sich ferner noch auf dem Querschnitt rundliche Gebilde, welche neben der charakteristischen Sprenkelung normalen quergestreiften Muskelgewebes in ihrem Innern Kerne enthielten, welche mit den Kernen von Riesenzellen vollkommen übereinstimmten. Zum Unterschied von Querschnitten normaler Muskelbündel fehlten die Sarcolemmkeme und waren die Querschnitte dieser Gebilde viel zu klein. Auf später hergestellten Längsschnitten erwiesen sich diese Dinge als schmale Bündelchen von quergestreiftem Muskelgewebe, in welchem sich zahlreiche Kerne vorfanden. Als was dieselben anzusehen sind, vielleicht als Ausgangspunkte einer Neubildung quergestreiften Muskelgewebes, muss dahin gestellt bleiben.

In der Ungebung dieser veränderten Partien der Bauchmusculatur fand 
ich, allerdings ganz vereinzelt, an normalen Muskelbündeln in Karyomitose begriffene Sarcolemmkerne.

9.

12 Tage. Uterus. Operation am 21. April 1886, Excision eines Stückchens der Uteruswand aus einem der bereits nit einander verbundenen Uterushörner.

Section am 3. Mai 1886. Die Wunde ist an einer Stelle mit der Bauchwand verklebt; keinerlei entzündliche Erscheinungen.

Mikroskopischer Befund. Der Defect reicht bis in's Lumen des. einen Uterushorns und ist durch ein voluminöses Blutgerinnsel ausgefüllt. Letzteres entbält viel Fibrin und ist in den mit den Wundrändern zusammenstossenden Theilen reichlich mit jungen Bindegewebszellen durchsetzt, welche anf der der Serosa entsprechenden Seite bereits einen continuirlichen Abschluss des Blutgerinnsels von der Bauchböhle bilden. Aus zahlreichen innerhalb solcher Zellen gelegener Karyomitosen ist zu schliessen, dass durch eine allmählich von den Wundrändern aus fortschreitende Organisation dieses Blutgerinusels eine Ausfüllung des Defectes durch Gewebe erzielt werden dürfte. Auch hier findet man den von den Fäden umschlungenen Theil der Uteruswand nekrotisch. Wie das Bindegewebe in der Umgebung des Defectes, so enthält auch die Muscularis an dieser Stelle und auch noch in weiterer Entfernung vom Defect Hitosen in mässiger Menge. Auffallend ist, dass die Ringrnuseulatur des nicht verletzten anderseitigen Uterusborns, das allerdings mit dem verletzten in continuirlichem geweblichen Zusammenhang stebt, in Karyomitose begriffene Muskelfasern, wenn auch in geringer Menge, enthält.

In den Epithelien der Schleimhaut und ibrer Drüsen kommen ebenfalls Mitosen vor, jedoch ohne dass man constatiren könnte, dass an Stellen, die dem Defect näher liegen, dieselben in grösserer Anzahl vorbanden seien, als an entfernteren. Auch die Epithelien des nicht verletzten Horns sind hin und wieder in Kerntheilung begriffen.

Um die Fäden, deren einzelne Fasern von Bindegewebszellen mehr oder weniger auseinandergedrängt sind, gruppiren sich mitunter schon recht allsehnliche Riesenzellen. Neben diesen fanden sich nicht selten in Kerntheilung begriftene Bindegewebszellen.

10.

13 Tage. Magen. Operation am 3. August 1886. Um eventuell auch am Magen die Vorgänge bei einer Hypertrophie zu beobachten, wurde eine Stenose des Pylorus dadurch herbeizuführen gesucht, dass in der uninittelbaren Näbe desselben 6 starke Seidenfäden nach Art einer Jobert'schen Darmaht in Entfernungen von circa $5 \mathrm{~mm}$ von einander eingelegt wurden. Es wurde bezweckt durch die Knüpfung dieser Fäden eine sich nacb dem Lumen des Pylorus hin vorwölbende Falte der Magenwand zu erzeugen, welche zu einer erschwerten Ausstossung des Mageninhalts führen und so eine Arbeitshypertrophie der Musculatur hervorrufen sollte.

Section am 16. August 1886. 
Mikrosk opischer Befund. Die Muskelfasern erseheinen in Schnitten, die sowohl der Pylorusgegend entnommen sind, als auch aus anderen Gegenden des Magens stammen, gegenüber den sonst gewohnten Diwensionen der Muskelfasern des Kaninchenmagens entschieden vergrössert und verdickt, was man wohl als Ausdruck einer bestehenden Hypertrophie ansehen könnte. Jedoch konnter karyomitotische Figuren, die lediglich auf eine in Folge der Hypertrophie stattfindende Zellvermehrung hingedeutet hă̈tten, nirgendwo gefunden werden. Dieser Befund würde mit den Erfahrungen, die Herczel bei seinen Untersuchungen über compensatorische Muskelbypertrophie bei Darmstenosen (Zeitschrift für klinische Medicin, Bd. 11 S. 321) machte, übereinstimmen, der oberhalb der Stenose hypertropbische Muskelzellen, aber kejne Anzeigen directer oder karyomitotischer Theilung der Kerne fand.

Indessen möchte ich von einer auch nur andeutungsweisen Beantwortung dieser Frage auf Grund dieses einen Präparates absehen, dagegen meinem Material noch einige Beobachtungen hinzufügen, die ich gerade an diesem Präparat bei der Untersuchung der durch die eingelegten Fäden gesetzten Verletzung des Muskelgewebes gemacht habe.

In der Timgebung der durch die Muscularis gelegten Fäden befindet sich zunächst eine Schicht jungen Bindegewebes, in welchem isolirte Muskelzellen um so bäufiger auftreten, je mehr man sich von stark roth gefärbten.Seidenfasern entfernt und der compacten Musculatur nähert. Zwischen und neben der. Seidenfädchen, auch wohl diese vollkommen umschliessend, aber auch von ihnen getrennt im Gewebe liegend, findet man eine grosse Anzahl verschieden grosser und verschieden gestalteter Riesenzellen. Auch innerhaib umschriebener, wie der Durchschnitt eines Kanals aussehender Stellen, die vermuthlich Stichkanäle darstellen, welche bei der Operation nicht zum Einlegen von Fäden benutzt wurden, findet man solche Riesenzellen von erheblichem Umfang.

Da es sich hier ja auch um eine Verletzung handelt, so fehlen hier auch keineswegs Zeichen von Regeneration. Besonders lebhaft wuchert noch das Bindegewebe, welches sich im Umkreis der Fäden befindet und zwischen die einzelnen Fasern derselben hineingewnchert ist. Dieses zeigen die in grosser Menge vorbandenen Mitosen an. Auch in den letztbeschriebenen, nicht von Fäden ausgefüllten Stichkanälen liegen zwischen den Riesenzellen mehrfach in Karyomitose begriffene Bindegewebszellen.

Aber auch die Muskeln der Umgebung betheiligen sich an den Wucherungszuständen in Gestalt nicht unerheblicher Mengen in indirecter Theilung begriffener Muskelzellen und intermusculärer Bindegewebszellen. Solche Muskelfasern finden sich nicht nur unter den von Bindegewebe isolirten, sondern auch in der dem Ort der Verletzung ferner gelegenen compacten Musculatur in einem bestimmtęn, aber verbältnissmässig weiten Umkreis. Auch in Endothelien von Capillaren fanden sich innerhalb der in Wucherung Jegriffenen Umgebung der Fäden Mitosen, wenn auch nur in geringer Menge. Auch an grösseren Gefässen sah ich hin und wieder Mitosen in der Wand and im adventitiellen Gewebe.

Arobiv f. patiol. Anat, Bd. CIX, Hit. 3 . 
Die Riesenzellen, welche ich sehr sorgfältig auf karyomitotische Theilungsfiguren der Kerne untersuchte, scheinen auf diesem Wege kaum eine Vermehrung ihrer Kerne zu erfahren, denn sonst müsste ich deren entschieden viele gefunden haben. Allerdings gelang es mir bei einer einzigen eine Mitose aufzufinden.

Die Dräsenepithelien der Mucosa enthielten Mitosen in geringer Menge und waren eher an Stellen zahlreicher, die von der Verletzung der Muscularis ferner als ihr näher gelegen waren.

11.

14 Tage. Magen. Operation am 6. April 1886, Section am 20. April. An den meisten Präparaten ist die Muskelwand des Magens ganz durchtrennt, so dass das sicb zwischen die Wundränder einschiebende Narbengewebe unmittelbar mit der Submucosa zusammenhängt. An einzelnen Prăparaten, wo auffallend viele Seidenfäden liegen, findet man vielleicht durch deren Umschnürung veranlasst, nekrotische Muskelpartien, in denen jegliche Kernfärbung ansgeblieben ist und wo das Protoplasma der Muskelzellen byalin und nicht gekörnt erscheint. Ausserdern sind die Muskeln wellig geschlängelt und zum Theil mit chromatophilen Körnchen verseben.

Die Neubildung von Zellen ist noch ziemlich lebhaft innerhalb des den Defect ausfüllenden Granulationsgewebes, ferner finden sich aucb Kerntheilungsfiguren in der Submucosa, wo dieselbe mit dem Defeet in Berührung steht und in der nächsten Umgebung dieser Stelle, freilich in geringer Menge.

Die Muscularis enthält im Allgemeinen nur noch mässig viele Mitosen. Auch in der Muscularis mucosae kommen bisweilen ziemlìch erhebliche Mengen von Mitosen vor an Stellen, die dem Defect nahe gelegen sind. Mitosen in Gefässendothelien fand ich nur vereinzelt und anf Theile der Narbe beschränkt, die noch in lebhafterer Wucherung begriffen waren. Neben und zwischen den Seidenfäden findet man in nicht gerade erheblicher Zahl und von geringer Grösse Riesenzellen, daneben öfter Mitosen in Bindegewebszellen.

Die Mucosa, an der an senkrecht auf die Magenwand gerichteten Schnitten schon makroskopisch eine Verbreiterung an mit dem Defect correspondirenden Stellen auffällt, enthält in der ganzen vorn Schnitte umfassten Strecke nicht unbedentende Mengen von in Karyomitose begriffenen Drüsenepithelien, welche um so zahlreicher sind je näher sie dem Defect liegen. Sie überwiegen durchaus in den oberen Theilen der Drüsensehläuche, feblen ganz auf der Magenimnenfläche und sind in der Năhe der Muscularis mucosae äusserst spärlich.

12.

17 Tage. Magen. Operation am 8. Sept. 1886. Es wurde in des

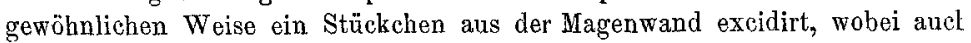
die Schleimhaut etwas lädirt wurde. In Folge dessen trat eine ziemlicl heftige Blutung ein, die nach der Vernähung der Wunde stand.

Section am 25. Sept. 1896. Bei der Eröffnung des Bauches gerieth mar seitlich von der Bauchwunde, die mit dicken Barken übernogen war, in ein 
zwischen den Bauchmuskeln gelegene, etwa markstïckgrosse, mit milehig gefärbtem Eiter gefüllte Höble. Mit der Wundnaht war innerlich der in der Nähe liegende Dickdarm und eine Dünndarnseblinge verwachsen. Ueber der eigentlichen Magenwunde Iag der unterste Theil des linken Leberlappens und war zit dem Magen an dieser Stelle fest verwachsen. Es musste deshalb ein Stück Leber mit herausgenommen werden. Beim Durehschnitt durch das Präparat senkrecht zum Verlanf der Wunde zeigte sich ein zwischen Leber und Magen befindlicher abgekapselter Eiterheerd von der Grösse etwa einer kleinen Erbse.

Mikroskopischer Befund. Der recht bedeutende Defect, der in manchen Präparaten bis in die Muscularis mucosae, ja bis in die Mucosa dringt, ist durch Bindegewebe ausgefüllt, welches vorzugsweise aus Spindelzellen besteht und an manchen Stellen schón die beginnende Umwandlung in sternförmiges Narbengewebe erkennen lässt. Mit diesem den Defect erfüllenden Gewebe steht in directem Zusammenhang eine Bindegewebsmasse, welche der Serosa ausserhalb der Wundränder noch eine sehr erbebliche Strecke weit aufliegt und auf der entgegengesetzten Seite in ebenfalls weiter Ausdehnung mit der Leber innigst rerwachsen ist. Dieses Bindegewebe zeigt in Allgemeinen anch bereits die Merkmale längeren Bestehens; denn es sind in ihm nur noch relativ wenig Kerne enthalten und es lässt sich fast an allen Stellen die Bildung von Fibrillen deutlich erkennen. Inmitten dieser recht ansehnlichen Bindegewebsmassen befindet sich eine fast kreisrunde Lücke, die bereits makroskopisch auffällt und deren Durchmesser etwa 2 bis $3 \mathrm{~mm}$ beträgt. Diese ist nichts Anderes als der Durchschnitt jenes bei der Section gesehenen abgekapselten Eiterbeerdes. Der Inhalt desselben feblt natürlich, indessen gestatten einige kleine Reste die an den Wandungen der Abscesshöhle hängen geblieben sind, über die Natur des Exsudates Aufschluss zu erbalten. Dass es sich wirklich um Eiter handelt, beweist das zahlreiche Vorhandensein von Leukocyten. Die Hauptmasse dieser Reste bilden aber zum Theil stark gefärbte Körnchen, welebe wobl als zerfallene Leukocyten aufzufassen sind. Die Wandungen dieses Abscesses bestehen überall aus jungem Granulationsgewebe, in welchem reichliche Karyomitosen auf eine lebhafte Production neuer Zellen hinweisen.

Im Grossen und Ganzen ist aber das Gewebe innerhalb und in der Umgebung des Defectes nur noch wenig in regenerativer Tbätigkeit begriffen. In der Narbe selbst findet man nur sehr selten Mitosen, ebenso in dem zwischen Magen und Leber befindlichen Bindegewebe. Ebenso wenig konnte ich an Gefässen irgend welche Wucherungszustände constatiren.

Die Muscularis ist leider quer getroffen, was das Auffinden von Mitosen in derselben erheblich erschwert, da der Querschnitt nur in günstigen Fällen eine Kerntheilungsfigur zur Anschanung bringt und hier an sich nur noch relativ wenig Figuren zu erwarten sind. Trotzdem war es mir hin und wieder möglich, eine Mitose in einem solchen Muskelquerschnitt aufzufinden. Die Muskelzellen erscheinen am Rande des-Defectes rom Bindegewebe der Narbe auseinander gedrängt. Auch fanden sich hin und wieder von Binde- 
gewebe bereits umschlossene und von der normalen Musculatur getreninte Häufchen nekrotischer Muskeln, welche ich in mehreren Präparaten von Riesenzellen eingeschlossen sab. Endlich traf ich auch in einem Präparat eine Riesenzelle, welche gar keinen Inbalt, mehr batte und dicht daneben eine solche, die einen Haufen bröckeliger, ungefärbter Massen enthielt, deren Natur als nekrotische Muskeln an sich nicht mehr erkenubar war, aber nach den übrigen Beobachtungen nicht mehr zweifelhaft sein dürfte. Danach scheint also auch eine Resorption solcher nekrotischen Muskeln durch Riesenzellen besorgt werden zu können.

Die Muscularis mucosae erscheint an Stellen, die der Narbe nahe gelegen sind, gegenüber ferner gelegenen entschieden verbreitert, so dass man hier den Effect der Hyperplasie mit dem Maassstab messen kann. Kerntheilungsfiguren sah ich jedoch nur noch äusserst selten in derselben.

In einzelnen Präparaten dringt der Defect noch durch die Muscularis mucosae. Hier stösst die Narbe direct mit der von der Bauchhöhle aus freigelegten Mucosa zusammen und rerbindet sich mit den Enden des bindegewebigen Stützgewebes der Mucosa, während die Drüsen an dieser Stelle in den Maschen, die theils von dem erhaltenen Stützgewebe, theils aber von Theilen des Narbengewebes gebildet werden, liegen. Die Drüsen selbst zeigen keine auffälligen Veränderungen, sind höchstens durch das Trauma oder den Zug des schrumpfenden Narbengewebes in ihrer Lage etwas verändert, in so fern sie meist an dieser Stelle mehr quer getroffen sind, während sonst in der ganzen Mucosa Längsschnitte der Drüsenschläuche vorhanden sinrl. In einem Präparat fand ich an einer solchen Stelle nicht nur im Narbengewebe und der durchtrennten Muscularis mucosae, sondern auch in Epithelien von Drüsen, in ersteren nur vereinzelt, in letzteren jedoch reichlicher Kerntheilungsfiguren, während dieselben sonst an Stellen, die der Muscularis mucosae nahe liegen, ganz fehlten, oder doch wenigsteus extrem selten waren.

In der Mucosa fanden sich sonst an den typischen Stellen Mitosen, wenn auch nicht in sebr erheblicher Menge.

In Präparaten, wo Seidenfäden mit durchschnitten waren, erwiesen sich die dieselben zusammensetzenden Fäsercben von vielen grossen Riesenzellen und Bindegewebszellen auseinander gedrängt und umwuchert. Solche Stellen zeichneten sich auch noch durch den Reichthum an Bindegewebszellen, die in Kerntheilung begriffen waren, aus.

13.

21 Tage. Magen. Operation am 18. August 1886, Section am 8. September 1886. Wunde gut geheilt, mit membranartigen Massen bedeckt.

Mikroskopischer Befund. Das Präparat bann in so fern als misslungen betrachtet werden, als darin eine klare Ansicht der Verhältnisse der in Heilung begriffenen Wunde nicht hervortritt. Es war das die Folge davon, dass die Wunde wegen der membranartigen Bedeckung nicht deutlich zu sehen war, und die Schnittrichtung nicht so ausfiel, wie es zu wünschen gewesen wäre. 
Nichtsdestoweniger kann das Präparat dazu dienen, die Verhältnisse der Muskeln in der Gegend der durch die vorhandenen Seidenfäden angedeuteten Defectstelle, so weit sie für den 21. Tag der Verheilung der Zahl der in ihnen enthaltenen Mitosen in Betracht kommen, darzulegen. Es finden sich danach nur noch verbältnissmässig spärlich in Kerntheilung begriffene Muskelzellen.

Die schon erwähnten Membranen auf der äusseren Magenoberfläche erweisen sich mikroskopisch als die Ausläufer einer breiten, stark vascularisirten Bindegewebslage, die der Magenoberfläche aufliegt und nach dieser zu mehr den Charakter jüngeren Granulationsgewebes trägt und aus zablreichen jungen, zum Theil in Karyomitose befindlichen Zellen besteht, wäbrend die der Bauchböhle zugekehrten Theile schon viel Fibrillen und nur relativ wenig Zellen und Kerne enthalten. Innerhalb dieser Bindegewebslage findet man die Enden und die Knoten der zur Naht gebrauchten Seidenfäden. Die einzelnen Fäserchen derselben sind von zum Theil spindelförmigen, zum Theil mehr rundlichen Bindegewebszellen auseinander gedrängt, und dass hier noch Neubildung von Zellen stattfindet, beweisen die zahlreichen Kerntheilungsfiguren in solehen Zellen. Daneben aber findet man grosse, schön ausgebildete Riesenzellen in enormen Mengen. Dieselben schliessen die Seidenfäden oftmals förmlich in sich ein und haben daher auf Längsschnitten eine sehr langgestreckte Gestalt. Mitunter findet man aber anch frei im Gewebe liegende Riesenzellen, die keine Fasern mehr umschliessen. Hier scheint wobl die Resorption der Fremdkörper bereits vollendet zu sein. Auch fand ich an den in diesem Bindegewebslager sehr zahlreichen jungen Gefässen wiederholt Mitosen in Endothelzellen, und zwar nicht blos in Capillaren, sondern auch in grösseren, eine Muskelwand besitzenden Gefässen.

Auch bier bemühte ich mich, in Riesenzellen Mitosen zu constatiren, fand aber nur eine einzige, bei der die Kerntheilungsfigur nocb dazu wenig schön ausgebildet war.

In der Mucosa sind die Karyomitosen in Epithelzellen der Drüsen ziemlich reichlich. Auch hier findet man sie nur an dem schon oft constatirten Ort in den oberen Theilen der Drüsensehläuche. Dass auch die Bindegewebszellen des Stützgewebes an der Wucherung Theil nehmen, fand ich hier öfters durch Karyomitosen in denselben bestätigt.

Controlstückcben aus dem Nagen und Dünndarm, welche ron normalen Stellen genommen wurden, ergaben in Bezug anf das Verhalten der Schleimhaut, dass:

1) im Magen Mitosen der Drüsenepithelien zerstreut vorkommen, aber auch hier auf das obere Ende der Drüsenschläuche beschränkt sind und auf der Oberfläche ganz fehlen;

2) im Dünndarm in allen Theilen der Mucosa grosse Mengen von Mitosen vorbanden sind, dagegen auch hier dem Oberflächenepithel der Zotten fehlen.

14.

25 Tage. Magen. Operation am 15. März 1886, Section am 8. April. Verwachsung der Operationsstelle mit dem Netz. 
Mikroskopischer Befund. Der Defect, welcher zwischen beiden durch die Operation rerletzten Muskellagen liegt, ist durch Bindegewebe ausgefüllt, in welches sich von beiden Seiten durch Bindegewebszellen mehr oder weniger isolirte Muskelzellen hineinerstrecken, jedoch ohne sich in der Mitte zu treffen. Zum Theil zeigt das Narbengewebe schon die Charakteristica des schrumpfenden Bindegewebes und ist dem entsprechend an einzelnen Stellen schon mit den bekannten stern- und spindelförmigen Zellen durchsetzt. Mit der Narbe und dem benachbarten Theil der Serosa ist das Netz verwachsen.

Im Allgemeinen findet man nur noch in sehr geringem Maasse Anzeigen von Zellvermehrung. Im Bindegewebe trifft man nur noch sehr wenig Mitosen und diese fast nur noch in der Umgebung von Seidenfäden. Daneben kommen in reichlicher Menge wohl ausgebildete Riesenzellen von mitunter sehr erbeblicher Grösse vor.

Innerhalb der Muscularis sind Mitosen extrem selten, in vielen Präparaten ist sogar an dieser Stelle keine einzige mehr aufufinden.

Auch fehlen jegliche Kerntheilungsfiguren in Capillarendothelien.

Ganz auffallend reichlich sind dem gegenüber Kerntbeilungsfiguren in den Epithelien der Magendrüsen. Sie beschränken sich auch hier auf den oberen Theil der Drüsenschläuche, fehlen aber auf der Oberfläche der Mucosa ganz, und sind in der der Muscularis mucosae zu gelegenen Region, also im Fundus der Drüsen nur ganz vereinzelt vorbanden. Es fällt ferner auf, dass Stellen, die der Verwundung nahe liegen, entschieden mehr Karyomitosen aufzuweisen haben, als fernere. Leider konnte dies Verbalten nur in dem verhältnissmässig kleinen Gebiet der Mucosa, welches das mikroskopische Präparat bot, constatirt werden, da andere Stücke der Magenwand aus dem Defect ferner gelegenen Partien nicht conservirt waren. Entsprechend diesen Wucherungszuständen, an denen auch das interglanduläre Bindegewebe zweifellos Theil genommen hatte, - es fanden sich auch vereinzelt Mitosen in Bindegewebszellen zwischen den Drüsen - war die Mucosa an der Stelle der Verwundung im Vergleich zu ferner gelegenen Stellen entschieden verdickt, was sogar makroskopisch deutlich erkennbar war.

15.

30 Tage. Magen. Operation am 29. Mai 1886, Section am 29. Juni. Netz mit der verwundeten Stelle verwachsen und zwar durch eine sich knglig vom Magen abbebende, ca. $\frac{1}{2} \mathrm{~cm}$ dicke Gewebsmasse.

Mikroskopischer Befund. Der Defect in der Muscularis ist durch Narbengewebe mit den charakteristischen Spindel- und Sternzellen ausgefüllt. Dasselbe Gewebe setzt sich einmal in die ebenfalls verletzt gewesene Submucosa fort, andererseits geht es in jene oben erwähnte, sich von der Magenoberfläche abhebende Gewebsmasse über. Letztere bestebt lediglich aus Bindegewebe, welches in den dem Magen zu gelegenen Theilen älteren, in den von ihm abgewandten mehr jüngeren Datums zu sein scheint. In den jüngeren Partien dieser Gewebsmasse findet man noch hin und wieder Mi- 
tosen, vereinzelte derselben in Endothelzellen der dieses Gewebe reichlich durchziehenden Capillargefässe.

Was die Regeneration in der eigentlichen Magenwand betrifft, so ist dieselbe anscheinend bereits zum Stillstand gekommen. In der narbigen Ausfüllungsmasse des Defects, wie in den den letzteren umgebenden Muskelfasern war in keinem der Präparate auch nur eine karyomitotische Figur aufzufinden. Die Schnittrånder der Musculatur sind unregelmässig, die Muskelfasern sind hier einzeln oder in Bündeln von Narbengewebe auseinander gedrängt und ragen bald mehr, bald weniger weit in die Narbe vor. Die Continuität der Muscularis ist aber nirgendwo wieder hergestellt. In der Muscularis mucosae ist von Kerntheilungsfiguren auch keine Spur mehr vorhanden.

Auffallend ist, dass die Mucosa noch recht zahIreiche in Kerntheilung begriffene Epithelien enthält. Auch hier beschränken sich dieselben auf die oberen Theile der Drüsenschläuche. In einigen zur Controle von anderen Stellen des Magens entnommenen Stücken fanden sich Mitosen äusserst selten in der Mucosa, wenn aber, so lagen sie auch stets in den oberen Abschnitten der Drüsen.

Um die von Bindegewebe aus einander gedrängten Seidenfasern gruppiren sich auch hier grosse Mengen von Riesenzellen von beträchtlicher Grösse. An mehreren Stellen sieht man auch hier Seidenfasern vollkommen in eine grosse Riesenzelle eingeschlossen. Mitosen in Riesenzellen zu finden war mir in keinem Präparat möglich.

16.

Quetschung. 2 Tage. Darm. Operation am 23. Sept. 1886. Eine vorgezogene Dünndarmschlinge wurde an einer Stelle zwischen den Fingern und mit der Pincette stark gequetscht. Es trat danach sofort starke Füllung der Gefässe an dieser Stelle auf, so dass sich der Darw hochroth färbte. Um diese Stelle später bei der Section nicht zu verkennen, wurde in der Nähe derselben ein Seidenfaden durch die Darmwand gezogen, dieser lang abgeschnitten und der Darm sodann wieder in die Bauchböhle versenkt. Verschluss der Bauchhöhle wie gewöbnlich.

Section am 25. Sept. 1886. Die gequetschte Darmstelle war mit den anliegenden Dickdärmen leicht verklebt, liess sich aber ohne Mühe lösen. Der gequetschte Theil war noch in geringem Grade hyperämisch.

Mikroskopischer Befund. Auf der Oberfläche der gequetschten Stelle findet man mehrfach geronnenes Fibrin, welches jedenfalls zur Verklebung von Dünn - und Dickdarm gefübrt hatte. In den Maschen der Fibrinbälkchen liegen neben Leukocyten mit den charakteristischen Kernen, sebr blasse und wenig gekörnte Zellen, welche bisweilen in Karyomitose begriffen sind und als junge Bindegewebszellen aufzufassen sind. Die Folgen der Quetschung geben sich an vielen Stellen durch Hämorrhagien und Einlagerungen von geronnenem Fibrin in die Gewebe kund, besonders in dern lockeren Gewebe der Submucosa, welche häufig dadurch an Breite nicht unerheblich 
zugenommen hat. Die Darmwand exclusive Mucosa enthält an versehiedenen Stellen in verschiedener Menge, bisweilen aber haufenweise Leukocyten, ausserdem auch Rundzellen, so dass man annehmen muss, dass es sich um einen entzündlichen Prozess zweifelsobne handelt. Eine Folge derselben scheint auch eine ziemlich ausgedehnte Nekrose der Muskelfasern an einigen Stellen zu sein. Im Allgemeinen aber findet man sämmtliche Gewebe der Darmwand in einer regenerativen Wucherung begriffen. Das ist zu schliessen aus einer grossen Anzahl von Kerntheilungsfiguren, welche das Bindegewebe überall, die Muskeln an Stellen, die nicht nekrotisch sind, enthalten. Auf die Capillargefässe, welche zum Theil bedeutende Erweiterung und bisweilen Zerreissung ibrer Wand erfahren hatten, verwandte ich bei der Untersuchung viel Aufmerksamkeit und fand in Endothelzellen derselben, wenn auch nicht gerade sehr häufg, aber doch hin und wieder Mitosen. Auch an grösseren Gefässen, die mit einer stattlichen Muscularis versehen waren, fand ich wiederholt, und zwar in manchen Präparaten an ein und demselben Gefäss 3,4, ja noch wehr in Karyomitose befindliche Muskelzellen der Media.

Die Mncosa bat unter der Quetsehung anscheinend wenig gelitten, denn es fehlen im Allgemeinen Zeichen von erfolgten Hämorrhagien, wenn auch an ganz vereinzelten Stellen solche zu finden sind. Ohne Rücksicht auf eine bestehende Verletzung finden sich aber Hitosen in den Epithelien der Drüsenschlänche in grosser Menge und zwar im Unterschied zum Magen in den tiefer gelegenen Abschnitten in grosser Anzahl, während sie nach dem Lumen zu spärlicher werden und auf der Oberfläche gar nicht mehr vorbanden sind.

Der zur Wiedererkennung der lädirten Stelle des Darms eingefübrte Faden war in einigen Präparaten mitgetrofen. Io Gegensatz zu den gequetschten Stellen zeigte die Umgebung desselben mebr degenerative als regenerative Veränderungen. Die Muskelfasern, welche durch den eingelegten Faden eine Raumbeengung erfahren mussten, sind in der nächsten Umgebung des Fremdkörpers concentrisch angeordnet und plattgedrückt, aber in Folge dieser Beeinträchtigung zum Theil schon vollständig nekrotisch, zum Theil erst in Degeneration begriffen und mit vielen stark gefärbten Körnchen durchsetzt. Ausserdem sieht man hier vielfach bereits in $Z$ erfall begriffenes Blut, aber wenig. Kerntheilungsfiguren im umgebenden Gewebe. Dass von diesem Faden eine Einwirkung auf die von ibr theilweise sehr weit entfernten gequetschten Stellen ausginge, ist vollkommen ausgeschiossen. Es kann aber dieser differente Befund in der Umgebung des Fadens einerseits, an rein gequetschten Stellen andererseits nicht Wunder nehmen, da doch eine Quetsehung ein weit geringfügigerer Eingriff ist, als ein zu einer vollkommenen Gewebstrennung führender Schnitt oder Stich.

17.

Schwangerer Uterus. Es wurde bei Gelegenheit einer beabsichtigten Operation am Uterus Schwangersehaft constatirt und behufs späterer Untersuchang einer der mit Fötus und Placenta versehenen Abschnitte des Uterus- 
schlauches entfernt und die Wunde durch die Naht geschlossen. Das gewonnene Präparat wurde in gewöhnlicher Weise behandelt und zur Constatirung des Verhaltens der bypertrophischen Musculatur mit Saffranin gefärbt.

Mikroskopischer Befund. In dem Präparat ist ein Theil der Placenta vorhanden, und mit ibr in Verbindung ein Stück der Uteruswand mit 2 Muskejllagen, einer äusseren quer-, und ejner inneren längsdurchschnittenen. Die Placenta erweist sich zusammengesetzt aus lockerem, reticulärem Gewebe mit grossen vielgestaltigen Zellen. Ferner findet man die Durchschnitte der grossen placentaren Gefässräume. Nach dem Lumen des Uterus zu gelangt man zu den Uterindrüsen, wit einer einfachen Lage Cylinderepithel und in jene sich hineinerstreckend, von den Eihäuten losgerissene zweifellose Chorionzotten. Innerhalb der Bluträume, deren Wand aus einer blossen Lage von Endothelzellen bestebt, findet man meist Blut, das auffallend reich an Leukocyten ist, deren Kerne in Folge der Färbung scharf hervortreten.

Mitosen fanden sich:

1) im Stroma der Placenta in grosser Menge, ferner in Endothelzellen der Bluträume der Placenta an einzelnen Stellen;

2) in der Muscularis, wenn auch in geringer Zahl, nicht nur im intermusculären Bintegewebe, sondern auch in Muskelzellen selbst.

In den Epithelien der Mucosa bezw. der Uterindrüsen waren keine Mitosen vorhanden.

Wenu ich nun die Resultate meiner Untersuchungen noch einmal zusammenfasse, so ergiebt sich zunächst in Bezug auf die Verheilung der von mir verletzten Organe des Kaninchens im Allgemeinen Folgendes:

Der Defect wird sofort nach der Operation von einem Blutgerinnsel ausgefüllt, in welchem sich bald mehr, bald weniger geronnenes Fibrin abscheidet und die getrennten Theile der Organwand verbindet. Im Laufe des zweiten Tages nun beginnt in der Umgebung der Wunde ein Wucherungszustand in sämmtlichen die Wunde umgebenden Geweben. Besonders lebhaft ist dieselbe im Bindegewebe, welches allmählich vom $W$ undrande aus auf karyomitotischem Wege das Blutcoagulum organisirt. Die Energie dieser regenerativen Reaction steigert sich etwa bis zum 5. Tage, um dann langsam nachzulassen. Ich fand dieselbe am 25. Tage nur noch spurenweis und am 30. Tage waren alle Anzeigen von Zellvermehrung in der Umgebung und innerhalb des Defectes verschwunden. Ich muss noch hervorheben, dass die Anzeigen von Zellvermehrung nicht nur in der unmittelbaren Umgebung des Defectes zu finden waren, sondern stets innerhalb einer breiten, bisweilen recht bedeutenden Schicht des 
umgebenden Gewebes. Als Anzeigen für den Grad der Wucherungszustände in den verschiedenen Geweben dienten mir die Zahl der bekannten durch Saffraninfärbung schon bei mittelstarker Vergrösserung (Winkel, Objectiv No. 5, Ocular No. 3) stets deutlich in die Augen fallenden karyomitotischen Figuren. Ich habe dieselben in allen Lagen der verletzten Organe gefunden, um ein Beispiel anzuführen, am Magen in der Tunica muscularis propria, dem dazu gehörigen intermusculären Bindegewebe nebst Gefässen, in den Zellen der Submucosa, in der Muscularis mucosae und in der Mucosa sowohl in den. Drüsenepithelien, als in dem bindegewebigen Stützgewebe der Drüsen. Danach habe ich den Eindruck gewonnen, dass es der Natur bei einer bestehenden Verletzung eines blasen- oder schlauchförmigen Organs nicht allein darum zu thun ist, den Defect durch neues Gewebe zu verschliessen, sondern auch während der Verheilung die durch die Verletzung geschwächte Wand durch eine Hyperplasie der den Defect in weiterer Ausdehnung umgebenden Gewebe im Sinne Virchow's za stützen. Besonders beweiskräftig erschien mir in dieser Beziehung das Präparat No. 4, wo in der Umgebung des Defectes eine ziemlich ausgedehnte Nekrose der Tunica muscularis propria herrschte, und die Muscularis mucosae in ganz auffallend stürmischer Weise die Neubildung von Muskelzellen betrieb, ohne selbst von der Wunde mitbetroffen zu sein. Es scheint mir, dass hier die ja sonst kaum für die Festigkeit der Magenwand in Betracht kommende Muscularis mucosae vicariirend für den Halt der Magenwand aufzukommen hätte.

Der Befund einer Nekrose der den Defect umgebenden Muskelfasern gehörte unter meinen Präparaten nicht zu den Seltenheiten. Ich fand den ersten Beginn einer Degenerescenz der Muscularis bereits am 2. Tage der Verheilung (Präp. 2 und 16) und bin ausserdem auf die - morphologischen Besonderheiten dieser Muskelfasern näher eingegangen. In einzelnen Fällen konnte ich die Nekrose auf eine localisirte eitrige Entzündung zurückführen, in anderen Fällen war aber keine Spur von Entzündung vorhanden. Ich vermuthe, dass das Absterben der Muskelfasern, die überhaupt auf Störungen in ihren Lebensbedingungen sehr leicht zu reagiren scheinen, hier entweder 
Folge der Umschnürung von Seiten der zur Vereinigung der Wundränder benutzten Fäden gewesen ist, wodurch eventuell die Zufuhr von Nährmaterial vielleicht in Folge von Compression grösserer Gefässe beeinträchtjgt wurde, oder dass man es mit einer oberflächlichen Einwirkung der Antiseptica, die im einzelnen Falle vielleicht etwas zu concentrirt auf die frische Muskelwunde applicirt waren, zu thun hat. Wie dem nun auch sei, für den Vorgang der Heilung haben die nekrotischen Partien der Muscularis nur die Bedeutung, dass sie den Defect quasi vergrössern, insofern nehmlich zu erwarten ist, dass die nekrotischen Gewebe nach einiger Zeit ausgestossen oder resorbirt werden, und nun der Vorgang der Verheilung in derselben Weise von Statten geht, wie ich ihn oben geschildert habe.

Im Allgemeinen scheint jedoch eine eitrige Entzündung der Energie der Zellenvermehrung in der Umgebung des Defectes Abbruch zu thun. Dieses fiel mir wenigstens am Präparat No. 8 auf, wo ich nicht nur ein voluminöses eitriges Exsudat zwischen den Wundrändern fand, sondern auch die Umgebung des Defectes reichlich mit Eiterkörperchen infiltrirt sah. Dass alles Gewebe, welches von den Vereinigungsfäden umschlossen war, nekrotisch geworden und bis auf Spuren bereits verschwunden war, habe ich bei der Beschreibung des Präparats genauer ausgeführt. Es fand sich nun, dass in dem den Defect umgebenden Gewebe eine für den 10. Tag der Verheilung sehr geringfügige Menge von Mitosen vorhanden war; und es wäre danach denkbar, dass die in Betracht kommenden Zellen noch nicht im Stande gewesen sind, eine Vermehrung durch Theilung einzugehen, sondern ihre Kraft noch zum grössten Theil dazu zu verwenden hätten, der weiteren zerstörenden Wirkung des entzündlichen Virus Widerstand zu leisten. Eine weitere experimentelle Verfolgung dieser Frage hat mir leider nicht den gewünschten Aufschluss verschafft. Ich bemühte mich nehmlich, an einer Magenwunde durch Betupfen derselben mit verdünnten Crotonöl (Präparat 7) eine stärkere Entzündung hervorzurufen, was mir auch gelang. Am 7. Tage wurde die Heilung unterbrochen und es fand sich ein eitriges Exsudat und entzündliche Erscheinungen in der Umgebung des Defects, speciell eine ausgedehnte Nekrose der demselben anliegenden Musculatur, In- 
dessen war hier jenseits der letzteren die Regeneration von Seiten des mehr oder weniger normalen Gewebes bereits energisch im Gange, wie ich es bei Nekrosen ohne eitrige Entzündung oben beschrieben habe.

Ich möchte mich nach diesen Ausführungen über das allgemeine Bild der Heilung verletzter glatte Muskeln enthaltender Organe etwas eingehender den einzelnen Gewebsbestandtheilen im Speciellen bei der Heilung zuwenden. Als Norm will ich hierbei den Magen, der mir entschieden wegen seiner breiten Gewebsschichten die klarsten Bilder geliefert hat, wählen.

Die erste Lage, welche von der Verletzung getroffen ist, wäre von der Bauchhöhle aus gesehen die Serosa. Leider konnte ich aber deren Verhalten in meinen Präparaten deshalb nicht beobachten, weil stets das den Defect ausfüllende Blutcoagulum sich noch eine Strecke weit im Umkreis der Verletzung auf der Oberfläche des verletzten Organs verbreitete und häufig noch zu Verklebungen und Verwachsungen der verwundeten Stelle mit Nachbarorganen führte. Auch scheinen die Enden der zur Vereinigung der Wundränder eingelegten Seidenfäden bezw. die Knoten stets einen derartigen Reiz auf die Gewebe auszuüben, dass es über kurz oder lang zu einer Bindegewebswucherung auf der Oberfläche des Organs kommt, welche die Fädèn umgiebt und ihre allmähliche Resorption bewirkt. In dieser Beziehung sind die Präparate No. 13 und 15, wo recht bedeutende Auflagerungen von Bindegewebe auf die Oberfläche des Magens vorhanden waren, besonders lehrreich. Ich komme hierauf später noch einmal zurück. Genaueres über die Regeneration des Epithels der Serosa findet sich in Stilling und Pfitzner's Arbeit über die Regeneration der glatten Muskeln (Archiv für mikroskopische Anatomie Bd. XXVIII. S. 401). Nach ihnen schliesst sich der Defect der Serosa auf dem Wege der indirecten Kerntheilung.

Als zweite Schicht würde nun die kräftige Muscularis propria kommen, deren Verhalten ich im Allgemeinen bereits geschildert habe, Ich möchte aber die Gelegenheit ergreifen, mich über die Vermehrung der glatten Muskeln im Speciellen an dieser Stelle noch etwas näher auszusprechen und noch einiges positives Material, welches ich nicht bei der Betrachtung heilender Muskelwunden gewonnen habe, beizubringen. So fand ich 
in einem schwangeren Uterus des Kaninchens (Präp. No. 17) mehrfach unter der Erscheinung der Karyomitose sich theilende Muskelfasern und konnte nach einer blossen Quetschung am 2. Tage nicht nur in der Tunica muscularis propria des Dünndarms ziemlich viele, sondern auch in der Tunica media einiger grösserer Gefässe mehrfach Kerntheilungsfiguren enthaltende Muskelfasern finden (Präp. 16). Auch fand ich in einem grösseren Gefäss des Netzes (Präp. 6) eine Muskelfaser mit Kerntheilungsfigur.

Eine vollkommene Regeneration verlorenen Muskelgewebes scheint nach meinen Erfahrungen beim Warmblüter ebensowenig stattzufinden, wie nach den Beobachtungen Stilling's und Pfitzner's beim Salamander und Frosch. Es bildet sich vielmehr zwischen den getrennten Muskeln eine bindegewebige Narbe, und dass diese auch in späterer Zeit nicht mehr verändert werden dürfte, abgesehen von einer zunehmenden Schrumpfung des Narbengewebes, beweist das relativ frühe Aufhören aller Theilungserscheinungen in der Umgebung der Operationsstelle, speciell aber an den glatten Muskeln. Dass sich aber die Muskeln in der Umgebung der Wunde vermehren, steht ausser allem Zweifel. Als was man diese Vermehrung ansehen soll, vielleicht als einen vergeblichen Versuch der Muskeln, das Verlorene zu ersetzen, oder aber, worauf ich schon früher hindeutete als ein Mittel die Widerstandsfähigkeit der durch die Verwundung geschwächten Organwand zu vermehren, vermag ich nicht zu entscheiden.

Durch das Auffinden solcher Mengen von in Karyomitose begriffenen Muskelzellen ist ein neuer Beweis erbracht, dass die Neubildung glatten Muskelgewebes von den physiologischen Muskelzellen ausgeht und nicht durch Umwandlung von Bindegewebszellen. Denn, worauf Stilling und Pfitzner bereits mit Nachdruck hinweisen, ist bei gleicher Wahrscheinlichkeit der isogenen und allogenen Neubildung eines Gewebes die letztere als ausgeschlossen zu betrachten, wenn das Vorkommen der ersteren hinreichend bewiesen ist.

Was nun die morphologischen Verhältnisse der in Kerntheilung begriffenen Muskelfasern anbetrifft, so können wir, um Wiederholungen zu vermeiden, hier auf die ausfübrliche Beschrei- 
bung und Abbildung derselben bei Stilling und Pfitzner verweisen. Die Figuren entsprachen in ihren einzelnen Phasen durchaus den von Flemming an den Epithelzellen von Salamandra beobachteten nur mit Modificationen, welche selbstverständlich der lang ausgezogene, spindelförmige Zellleib und der lange, stäbchenförmige Kern mit sich bringt.

Mit den Schwierigkeiten, welche Stilling und Pfitzner bei der genaueren Beobachtung der in Kinese begriffenen Muskelkerne und deren Verhalten zum Zellleib empfunden haben, habe ich um so mehr zu kämpfen gehabt, als ich auf Schnitte angewiesen war, welche nur in seltenen Fällen die Ansicht einer genau im Längsschnitt vorliegenden Fasern gestatteten, während die genannten Forscher nach Entfernung der Mucosa die Muskelhaut des Magens von Triton taeniatus wegen ihrer Feinheit direct zur mikroskopischen Untersuchung ausbreiten konnten, und so stets den Längsschnitt der Muskelelemente vor sich hatten. Dagegen hatte ich wieder den Vortheil, dass wenn in einem Schnitt wirklich Muskelfasern im Längsschnitt getroffen waren, ich wegen der Feinheit meiner Präparate die Zellentouren besser verfolgen konnte. In Folge dessen habe ich das von Stilling und Pfitzner in Fig. 17 ihrer Tafel abgebildete und nur in einem Falle gefundene Stadium mehrfach beobachten können. Ferner aber habe ich eine beginnende Einschnürung des Zellleibs zwischen den beiden Kernen bereits an Fasern gesehen, wo die beiden Kerne nicht wie in Fig. 17 der Stilling-Pfitzner'schen Tafel eine bereits weitgehende Annäherung an das Ruhestadium zeigen, sondem in der Faser mit dem längeren Durchmesser nach quer gestellt, mehr dem Zustand der Kerne in Stilling's Abbildung No. 13 ähneln. Eine sehr schöne derartige Ansicht erhielt ich in der Muscularis des erwähnten schwangeren Uterus (Präp. 17).

Merkwürdig und soviel ich weiss noch nicht beobachtet, ist die nach Verletzung des muskulösen Theils speciell der Magenwand auftretenden Wucherungszustände innerhalb der zelligen Elemente der Mucosa. Um mich über das Vorkommen derselben an normalen Stellen des Magens zu überzeugen, untersuchte ich mehrfach Stïckchen, die ich einem operirten Magen an einer von der Operationsstelle weit entfernten Stelle ent- 
nommen hatte. Hier fand ich wenn überhaupt nur ganz vereinzelte in Karyomitose befindliche Drüsenepithelien. An Stellen, welche in der Nähe des Defectes liegen, finden sich nun bisweilen enorme Mengen von Mitosen und zwar nicht nur in Epithelzellen, sondern auch im interglandulären Stützgewebe. Es geht schon daraus hervor, dass es sich nicht nur um einen etwaigen Wiederersatz functionsunfähig gewordener Drüsenzellen handelt, woran man wohì denken könnte, vielmehr weist auch der Befund einer nicht unbedeutenden Verbreiterung der Mucosa an den betreffenden Stellen, wie ich sie mehrfach sogar makroskopisch constatiren konnte, auf eine wirkliche Gewebszunabme hin. Eine auffallende Erscheinung ist, dass am Magen diese Vermehrung der zelligen Elemente innerhalb einer ganz bestimmten Region der Mucosa stattfindet und zwar in der der inneren Oberfläche der Mucosa zu gelegenen Hälfte der Drüsenschläuche, während im Oberflächenepithel nie und in den der Muscularis zu gelegenen Partien der Mucosa äusserst selten Kerntheilungsfiguren zu finden waren. Jiese Neubildung von Zellen der Mucosa hält jedoch nicht gleichen Schritt mit den in den anderen Lagen des Magens nach einer Verletzung bestehenden Zelltheilungen. Wie an den andern Gewebsarten, so beginnt auch in den Mucosazellen die Vermehrung einige Zeit nach der Verwundung, steigert sich aber nur allmählich und erreicht, soweit ich aus meinen Präparaten bestimmen kann, erst in der vierten Woche - ich fand die meisten Mitosen an dieser Stelle an einem 25 Tage der Heilung überlassenen Magen - den Höhèpunkt, um dann allmählich wieder nachzulassen. Diese Incongruenz der Wucherungszustände in der Mncosa und in den übrigen Schichten des Magens erklärt es auch, dass zu einer Zeit, wo bereits alle übrigen Gewebe wieder zur Ruhe gekommen, in der Mucosa nicht unerhebliche Mengen von sich theilenden Epithelzellen noch zu finden sind.

Angaben über das Vorkommen von Kerntheilungsfiguren im Magenepithel finden sich in der Literatur noch äusserst selten. Ich fand darüber bei Sachs (Zur Kenntniss der Magenschleimhaut in krankhaften Zuständen, Archiv für experimentelle Pathologie und Pharmacie Bd. 22, S. 172). Folgendes: „Ueber Kerntheilungsfiguren im Magenepithel liegen bis jetzt meines Wissens 
keine Beobachtungen vor. Ich fand sie im Hundemagen nur dieses eine Mal (bei acuter Anämie); sonst habe ich sie weder unter normalen noch unter pathologischen Verhältnissen jemals wiedergesehen. Gleichwohl möchte ich ihr häufiges Vorkommen im vorliegenden Falle nicht als etwas Pathologisches bezeichnen. Bekanntlich treten die Kernfiguren gern heerdweis auf. Es ist daher sehr wohl möglich, dass die von mir mit Hämatoxylinalaun untersuchten Schleimhautpartien, die ja natürlich nur einen Bruchtheil der ganzen Màgenschleimhaut bilden, zufällig keine Figuren enthielten, während sie in anderen unbeachtet gebliebenen Partien vielleicht sehr zahlreich vorkamen."

Eine zweite Angabe über dieses Thema findet sich im Centralblatt für medicinische Wissenschaften $1886 \mathrm{~S} .83$, wo Bizzozero über eine Beobachtung Saccozi's (näheres Gazz. degli ospitali 1885 p. 147) berichtet, dass eine Regeneration der Epithelien der Magen- und Darmdrüsen bei natürlichem und künstlichem durch Abführmittel hervorgebrachten Schleimhautkatarrb. lebhafter wird.

Der Zusammenhang von Verwundung der Magenwand und dem Vorhandensein von Mitosen der Drüsenepithelien war in den von mir beobachteten Fällen zweifellos. Anders steht's mit dem Dünndarm und Uterus, wo ich ebenfalls in der Schleimhaut Mitosen fand. Im Dünndarm waren dieselben sogar in der Regel sehr zahlreich, erschienen aber vom Defect wenig beeinflusst zu sein, insofern sie nicht nur an Stellen vorhanden waren, die in der Nähe des Defects lagen, sondern ohne Rücksicht auf diesen den ganzen Querschnitt der Darmschleimhaut gleichmässig durchsetzten. Ja selbst in einem vollkommen unberührten Dünndarm, den ich von einem an einem andern Organ operirten Thier gewann, fand ich die Drüsenepithelien kaum minder so häufig in indirecter Theilung begriffen. Im Gegensatz zum Magen fanden sich die Kerntheilungen anf den Längsdurchmesser einer Drüse bezogen am reichlichsten in den der. Muscularis benachbarten Theilen, nahmen gegen das Lumen allmählich an Zahl ab und fehlten vollständig den die Zotten bekleidenden Epithelien.

Im Uterus waren Mitosen des Schleimhautepithels in einem Fall (Präp. 2) gar nicht vorhanden. In den mir sonst zur Verfügung stehenden Präparaten waren sie vorhanden, doch auch 
hier über die Mucosa im Allgemeinen gleichmässig vertheilt ohne Rücksicht auf die Stelle der Verletzung.

Wie ich schon bei der Besprechung der Narbenbildung herverhob, scheint mir die Ausfüllung des Defectes durch Bindegewebe dadurch zu Stande zu kommen, dass die am Rande des Defectes gelegenen Bindegewebszellen in Wucherung gerathen und allmählich das die Wundränder verbindende Blut-Fibringerinnsel organisiren. Die Zellvermehrung erfolgt dabei ebenfalls auf karyomitotischem Wege. Aber nicht nur bei der Narbenbildung beobachtete ich diesen Modus der Bindegewebsneubildung, sondern auch in jenen Fällen, wo eine entzündliche Bindegewebsneubildung auf der Oberfläche des verletzten Organs entstand, die eventuell zur Verwachsung desselben mit Nachbarorganen führte. Ich habe bereits früher darauf hingewiesen, dass der andauernde Reiz, den die als Fremdkörper wirkenden Fadenenden und Knoten auf die Umgebung ausübten, diese Bindegewebswucherungen hervorrief. Der Vorgang bei der Bildung dieses adhäsiven Bindegewebes ist etwa folgender: Anfangs wird die Verklebung des verletzten Organs mit einem Nachbarorgan bewerkstelligt durch eine Fortsetzung des den Defect ausfüllenden Blutcoagulums, welches die Wundränder meist seitlich noch eine Strecke weit überragt. Mit dem zunehmenden Zerfall der Blutzellen und vermehrter Bildung von Fibrin wird diese Vereinigung noch fester, während gleichzeitig von der Wand des verletzten, bisweilen auch des adhärenten Organs eine Bindegewebswucherung ausgeht, welche bestrebt ist, das noch leicht zerreissliche Verbindungsmaterial in widerstandsfähiges Gewebe umzuwandeln. In einem meiner Präparate (No. 6) fand ich beide Stadien neben einander: auf der einen Seite der Wunde nach Verklebung durch ein Blutcoagulam, auf der andern bereits eine rein zellige Verbindungsmasse mit wenig eingestreutem Fibrin. Dass auch hier das am Magen adhärente Netz in Wucherung gerathen war, und zwar in so ausgedehntem Maasse, dass sich selbst an Stellen, die in keiner directen Beziehung zu der Verwachsungsstelle standen, habe ich bei der Beschreibung des Präparates bereits hervorgehoben.

Das junge Granulationsgewebe ist stets stark vaseularisirt und der häufige Befund von Karyomitosen in Endothelzellen von 
Gefässen in allen den Fällen, wo überhaupt noch Bindegewebsproliferation vorhanden war, zeigt, dass diese sich bei dem Aufbau des adhäsiven Gewebes lebhaft betheiligen.

Von einer directen Betheiligung der stets in gewisser, nahe dem Defect sogar in reichlicher Menge vorhandenen Leukocyten an der Bindegewebsbildung konnte niemals eine Spur entdeckt werden. Die Leukocyten gehörten im Wesentlichen der polynucleären Form an und liessen niemals Andeutungen einer Karyomitose erkennen. Ich habe übrigens schon angegeben, dass ich die in den Präparaten vorhandenen chromatophilen Körnchen von zerfallenen Leukocyten glaube herleiten zu dürfen.

Die späteren Schicksale des adhäsiven Gewebes konnte ich in mehreren Präparaten beobachten. Es unterliegt denselben Umwandlungen wie das Bindegewebe überhaupt. So fanden sich am 17. Tage (Präp. 12) nur noch relativ wenig Kerne in demselben, aber schon viele Fibrillen und fast gar keine Mitosen mehr weder in eigentlichen Bindegewebszellen, noch in Gefässendothelien.

Während hier der Einfluss von Seidenfäden weniger hervortrat, war derselbe in Präp. 15 und 13 gar nicht zu verkennen. In Präp. 13 bestand überhaupt keine Adhäsion, sondern es war nur eine bedeutende, in membranartige Fetzen auslaufende Bindegewebsmasse auf die Organoberfäche aufgelagert und in Präp. 15, wo allerdings eine, aber nur unbedeutende Adhäsion des Netzes bestand, war die Auflagerung derartig massig, dass sie als ein vorspringender Tumor auf den ersten Blick imponirte. Hier wie dort am 21. und 30. Tage aber waren noch $W$ ucherungsvorgänge vorhanden, die sich besonders durch den Ort, wo sie bestanden, unterschieden. In Präp. 13 lag die Wucherungszone in der Nähe der Magenoberfläche, während die entfernteren der Bauchhöhle zugekehrten Theile die Zeichen schon längeren Bestehens zeigten; im Präp. 15 sind dagegen die mit der Narbe in Verbindung stehenden Partien älteren Datums als die der Bauchhöhle zugewandten oberflächlichen, wo an einzelnen Stellen sogar noch Neubildung von Bindegewebe erfolgte. Danach scheint also die Gewebszunahme sowohl durch eine Auflagerung neuen Gewebes auf die Oberfläche stattfinden, als auch aus dem Innern, also hier vou der Ursprungsstelle aus erfolgen zu können. 
In wie weit sich sog. Wanderzellen, d. h. emigrirte farblose Blutkörperchen an dem Aufbau derartiger Gewebe betheiligen, mag dahin gestellt bleiben; indessen scheint man in neverer Zeit je mehr und mehr davon abzukommen, derartige Metamorphosen einer Gewebsart in eine andere für möglich zu halten. Jedenfalls ist kein Grund anzugeben, warum die Natur einen solchen complicirten Weg einschlagen sollte, wo ihr doch stets ein weit einfacherer, nehmlich die Vermehrung der überall anwesenden Bindegewebszellen zu Gebote steht, um neues Bindegewebe, sei es nun zu welchem Zweck herzustellen. Und wenu man den jetzt doch im Allgemeinen anerkannten Grundsatz, dass wenn eine isogene Neubildung eines Gewebes in hinreichender Häufigkeit beobachtet ist, eine allogene, bei sonst gleicher Wahrscheinlichkeit ausgeschlossen ist, auch auf dieses Thema anwendete, so wäre allein dadurch schon die Frage aus der Welt geschafft, ob Leukocyten in der That eine Neubildung von Bindegewebszellen durch Metamorphose bewirken können. Was diesen Punkt bei der Narbenbildung anbelangt, so verweise ich nochmals auf die Arbeit Stilling's und Pfitzner's und auf das daselbst S. 402 - 404 Gesagte.

Ein kurzes Wort will ich noch den von mir so häufig gefundenen Riesenzellen widmen, welche innerhalb der Narbe und jenen auf die Magenoberfläche aufgelagerten Bindegewebsmassen, wo sich als Fremdkörper wirkende Seidenfäden befinden, an sich njchts Auffallendes haben. Man sieht dieselben ja im Allgemeinen als Vermittler der. Resorption solcher Fremdkörper an und es ist bekannt, dass selbst Seidenligaturen, wenn auch nur allmählich, vollkommen resorbirt werden. Zi egler schreibt darüber in seinem Lehrbuch der allgemeinen pathol. Anatomie 1884, S. 163: "Die Resorption ist indessen nicht an ihr Vorhandensein (nehmlich der Riesenzellen) geknüpft, sondern geht auch da vor sich, wo sie fehlen. Auffällig bleibt indessen ihr häufiges Auftreten an der Oberfläche von festen Körpern. Man darf sich vielleicht vorstellen, dass das Aufliegen einer Zelle auf einem Fremdkörper den Prozess der Zelltheilung hintanhält, ohne die Kerntheilung zu behindern." Ich möchte nun hinzufügen, dass ich bei den colossalen Massen von Riesenzellen, die ich in meinen Präparaten gesehen habe, nur in 2 Fällen, und hier auch nicht 
einmal in deutlicher Weise, karyomitotische Figuren in Riesenzellen gefunden habe, und es daher als sehr unwahrscheinlich erscheint, dass die Kernvermehrung innerhalb der Riesenzellen für gewöhnlich auf karyomitotischem Wege zu Stande kommt. Ich hätte sonst in meinen Präparaten, wo ich die Bildung von Riesenzellen in der Umgebung von Fremdkörpern (Seidenfäden) vom 10. Tage ab stets beobachtet und deren Ausbildung bis zu ungehenerer Grösse in der 4. Woche verfolgt habe, Kerntheilungsfiguren in Riesenzellen sehr häufig finden müssen.

Noch einmal möchte ich auf Präp. 7 und 8 hinweisen. In beiden war eine eitrige Entzündung der Operationsstelle eingetreten und im ersteren war die Leber mit dem Magen, in letzterem die Bauchwand mit dem Darm durch eine Schicht jungen Granulationsgewebes verwachsen. In beiden Fällen fand ich an der Verwachsungsstelle am Rande der Leber in dem einen, am Rande der quergestreiften Musculatur in dem anderen eigenthümliche degenerative Erscheinungen der betreffenden Parenchyme und in deren Nähe ebenfalls Riezenzellen. Da in beiden Fällen eitrige Entzündung herrschte, so bin ich geneigt, die Degeneration der Parenchymzellen als eine unmittelbare Folge der Eiterung zu betrachten, dagegen die Riesenzellen auch hier als Vermittler der Resorption anzusehen, welche die Aufgabe haben, die anscheinend verfetteten Zellen der Leber in dem einen Fall, die hyalin degenerirten Bündel der quergestreiften Bauchmusculatur im anderen Falle fortzuschaffen. Für letztere Ansicht sprechen meiner Meinung nach besonders noch die Bilder, wo innerhalb einer kranzförmigen Riesenzelle nur noch kleine Reste der degenerirten Musculatur zu finden sind. Dass endlich auch Riesenzellen nekrotische glatte Muskeln in einer in Heilung befindlichen Magenwand umgaben und in sich aufnahmen, konnte ich in einem Präparat (No. 12) beobachten. 